\title{
Nuevas formas de protección del consumidor en la contratación electrónica de servicios turísticos: los servicios de viaje vinculados *
}

\author{
New forms of consumer protection on contracts of tourism services concluded by electronic \\ means: linked travel arrangements
}

\author{
LUCÍA ALVARADO HERRERA \\ Profesora Titular de Derecho Mercantil \\ Universidad Pablo de Olavide (España) \\ lalvher@upo.es
}

https://orcid.org/0000-0002-9594-1983

\begin{abstract}
Resumen: La Directiva 2015/2302, de 25 de noviembre, relativa a los viajes combinados y a los servicios de viaje vinculados, modificó el régimen jurídico de los viajes combinados e introdujo la figura de los servicios de viaje vinculados. El objeto de este trabajo lo constituyen los servicios de viaje vinculados, procediéndose al análisis de los elementos que los configuran y diferencian de los viajes combinados, así como de los deberes que se imponen al empresario que facilita la contratación de servicios de viajes que finalmente acaban vinculándose. Todo ello desde la perspectiva de la finalidad perseguida por el legislador: aumentar la protección de quienes contratan servicios turísticos, especialmente en forma electrónica.
\end{abstract}

Abstract: The Directive 2015/2302 of 25 Novembre 2015, on package travel and linked travel arrangements, modified the legal regime of package travel and introduced the figure of linked travel arrangements. The object of this work is the linked travel services, proceeding to the analysis of the elements that configure and differentiate them from package travel, and the duties imposed on the trader

Cómo citar este trabajo: ALVARADO HERRERA, Lucía, "Nuevas formas de protección del consumidor en la contratación electrónica de servicios turísticos: los servicios de viaje vinculados", Revista de Estudios Jurídicos y Criminológicos, n. ${ }^{\circ}$ 3, Universidad de Cádiz, 2021, pp. 103-139, DOI: http://doi.org/10.25267/REJUCRIM.2021.i3.5

* Este trabajo se enmarca dentro del Proyecto de Investigación del Programa Estatal de Investigación, Desarrollo e Innovación Orientada a los Retos de la Sociedad RTI2018-096201-B-I00, denominado "Derecho Digital” y financiado por el Ministerio de Ciencia e Innovación, la Agencia Estatal de Investigación y el Fondo Europeo de Desarrollo Regional (FEDER). 
who facilitates the contracting of travel services that eventually end up being linked. All this from the perspective of the aim pursued by the legislator: to increase the protection of those who contract tourist services, especially by electronic means.

Palabras clave: protección del consumidor, viajero, servicios de viaje, servicios turísticos, servicios de viaje vinculados, viajes combinados, insolvencia, empresario.

Keywords: consumer protection, traveller, travel services, tourist services, linked travel arrangements, package travel, insolvency, trader.

Sumario: 1. INTRODUCCIÓN. 2. DEFINICIÓN Y CARACTERÍSTICAS DE LOS SERVICIOS DE VIAJE VINCULADOS. 2.1. Combinación del al menos dos tipos diferentes de servicios de viaje para el mismo viaje o vacación. 2.2. La combinación no constituye un viaje combinado. 2.3. El viajero contrata los servicios de viaje con cada prestador de servicios de viaje. 2.4. Facilitación de la contratación por el empresario en la forma legalmente prevista: clases de servicios de viaje vinculados. 3. DEBERES Y OBLIGACIONES DEL EMPRESARIO FACILITADOR. 3.1. Deber de información precontractual. 3.2. Obligación de constituir una garantía frente a su insolvencia. 4. CONCLUSIONES. 5. BIBLIOGRAFÍA.

\section{INTRODUCCIÓN}

Los servicios de viaje vinculados son combinaciones de servicios turísticos, distintas de los viajes combinados que, en opinión del legislador, merecen una cierta protección, es decir, una protección adicional a la prevista para la contratación de servicios turísticos sueltos, aunque menor que la reconocida a quien contrata un viaje combinado ${ }^{1}$.

Esa protección adicional se manifiesta fundamentalmente en que el viajero va a quedar protegido cuando alguno de los servicios turísticos que integra la combinación no se ejecute como consecuencia de la insolvencia del empresario que le ha facilitado la contratación de esos servicios y, por tanto, la formación de los servicios de viaje vinculados. Junto a esta protección, que podemos calificar como directa, se arbitran medidas tendentes a conseguir que el viajero, antes de quedar vinculado por este tipo de combinación, sea consciente de que no está contratando un viaje combinado. Ello se logra mediante la imposición de determinados deberes de información precontractual al empresario facilitador de los servicios de viaje vinculados, dando lugar a una protección del viajero de carácter indirecto.

\footnotetext{
${ }^{1}$ Vid. PEINADO GRACIA, J.I., "La protección del pasajero en el contrato de viaje combinado y en la prestación de servicios asistidos de viaje: la responsabilidad del transportista aéreo y de los operadores turísticos", en $L a$ responsabilidad del transportista aéreo y la protección de los pasajeros (dir. Guerrero Lebrón, M.J.), Madrid, Marcial Pons, 2015, p. 549.
} 
Los servicios de viaje vinculados han nacido de la mano de los viajes combinados. Éstos fueron regulados por primera vez en la Directiva 90/314/CEE del Consejo, de 13 de junio de 1990, relativa a los viajes combinados, las vacaciones combinadas y los circuitos combinados. Esta norma fue objeto de transposición al Ordenamiento jurídico español mediante la Ley 21/1995, de 6 de julio, reguladora de los viajes combinados. Más adelante, el Texto Refundido de la Ley General para la Defensa de los Consumidores y Usuarios (en adelante, TRLGDCU) refundió en un único texto la Ley 26/1984, de 19 de julio, General para la Defensa de los Consumidores y Usuarios y otras normas de transposición de directivas en materia de consumidores, entre las que se encontraba la citada Ley 21/1995. Desde ese momento, el contenido de la Ley 21/1995 -es decir, el régimen jurídico de los viajes combinados- se recogió en el Libro IV del TRLGDCU.

Desde la aprobación de la Directiva 90/314, el sector turístico había experimentado un notable cambio y evolución debido a la irrupción de Internet y de las tecnologías emergentes, que alteraron profundamente la forma en que los servicios turísticos eran contratados. De una contratación fundamentalmente presencial -y en ocasiones, por vía telefónica- se inició una tendencia a la contratación electrónica de estos servicios ${ }^{2}$. Los viajes combinados no fueron una excepción a esta tendencia, pero presentan la peculiaridad de que las nuevas formas de contratar los servicios turísticos han influido en el propio concepto de viaje combinado.

En efecto, tanto en la Directiva 90/314 como en la Ley de trasposición española, la existencia de una organización previa por parte de un empresario (con las matizaciones realizadas posteriormente por la jurisprudencia de la Unión Europea) constituía un requisito esencial para afirmar la existencia de un viaje combinado. La contratación electrónica de servicios turísticos permite que el resultado del viaje combinado (combinación de varios servicios turísticos en un solo "producto de viaje") se produzca con la participación activa del viajero. Se alteran de facto los roles o papeles que en la formación de la combinación desempeñan el organizador y el viajero: la organización del viaje puede dejar de estar exclusivamente en manos del empresarioorganizador, para ser compartida o incluso desarrollada con más intensidad por el viajero.

El problema residía en que las nuevas formas de contratación daban como resultado productos turísticos en apariencia igual a los viajes combinados pero que, al no reunir los requisitos exigidos por la Directiva ni la Ley, quedaban fuera de su ámbito de aplicación. Se generaba, por tanto, una desprotección para el viajero, que creía estar contratando viajes combinados cuando en realidad contrataba servicios sueltos ${ }^{3}$.

\footnotetext{
${ }^{2}$ La irrupción de Internet permitió, además, la comercialización directa de los servicios de viaje por los propios prestadores de esos servicios (aerolíneas, establecimientos hoteleros, etc.), a través de sus páginas webs [vid. BATUECAS CALETRIO, A., "La contratación de viajes vinculados", Revista Doctrinal Aranzadi CivilMercantil, núm. 6, 2016 (edición digital), pp. 2-3, que se detiene en analizar las ventajas que ello supone para estos operadores].

${ }^{3}$ A lo que había que añadir, como apunta acertadamente BERENGUER ALBALADEJO ["Luces y sombras de la nueva Directiva (UE) 2015/2302 del Parlamento Europeo y del Consejo de 25 de noviembre de 2015, relativa a
} 
Además, estas combinaciones que no quedaban sujetas a la Directiva eran ofrecidas por operadores distintos de las agencias de viajes (piénsese en el caso en el que en la web de una aerolínea se adquiere un billete de avión y se reserva una habitación de hotel en el punto de destino). Estos operadores ofrecían de hecho el mismo producto que las agencias de viaje (el viaje combinado) pero no estaban sometidos a las disposiciones de la Directiva responsabilidad por la ejecución del viaje combinado, obligación de constituir una garantía que cubriera su insolvencia, etc.-, generándose distorsiones en la competencia ${ }^{4}$.

Por todo lo expuesto, y con la finalidad de adecuar la normativa europea a las nuevas exigencias del mercado turístico, se inició en el año 2007 un proceso de reforma de la regulación de los viajes combinados, que se plasmó en la Directiva 2015/2302, de 25 de noviembre, relativa a los viajes combinados y a los servicios de viaje vinculados (en adelante, Directiva 2015/2302) incorporada a nuestro Ordenamiento jurídico mediante el Real Decreto-ley 23/2018, de 21 de diciembre, de transposición de directivas en materia de marcas, transporte ferroviario y viajes combinados y servicios de viaje vinculados 6 . El Real Decreto-ley modifica el Libro IV del TRLGCDU, que contiene ahora la regulación de los viajes combinados y de los servicios de viaje vinculados ${ }^{7}$.

los viajes combinados y a los servicios de viaje vinculados", Internacional Journal of Scientific Managment Tourism, vol. 2, núm. 2, 2016, pp. 35-36], la incertidumbre que tal situación generaba en los prestadores de servicios turísticos, pues al no existir seguridad sobre la naturaleza del producto ofrecido (viaje combinado o no), quedaba en la indefinición el régimen jurídico aplicable, mucho más gravoso si la relación jurídica llegaba a calificarse de viaje combinado en lugar de considerarse que se estaban contratando servicios turísticos sueltos.

${ }^{4}$ Vid. sobre esta cuestión GONZÁLEZ FERNÁNDEZ, M.B., "Redefiniciones y armonización en materia de viajes combinados", Revista de Derecho Mercantil, núm. 297, 2019 (edición digital), I.

${ }^{5}$ Directiva 2015/2302 de 25 de noviembre relativa a los viajes combinados y a los servicios de viaje vinculados, por la que se modifican el Reglamento (CE) no 2006/2004 y la Directiva 2011/83/UE del Parlamento Europeo y del Consejo y por la que se deroga la Directiva 90/314/CEE del Consejo (DOCE L 326, de 11 de diciembre). La Directiva debía haberse incorporado como muy tarde el 1 de enero de 2018 y sus preceptos aplicarse a partir del 1 de julio del mismo año (art. 28, 1 y 2 de la Directiva); no obstante, hasta marzo de 2019 no se completó el proceso de incorporación en todos los Estados miembros. Sobre los antecedentes de la Directiva vid., entre otros, Comunicación de la Comisión al Parlamento Europeo, al Consejo, al Comité Económico y Social Europeo y al Comité de las Regiones "Adaptar la normativa europea sobre viajes combinados a la era digital”, COM (2013) 513 final, Bruselas, 9 de julio de 2013 (disponible en https:/leur-lex.europa.eu/legalcontent/ES/TXT/PDF/? uri=CELEX:52013DC0513\&from=ES); PANIZA FULLANA, A., Viajes combinados y servicios de viaje vinculados: replanteamiento de conceptos y sus consecuencias sobre la responsabilidad, Madrid, Dykinson, 2017, pp. 23-28; FELIÚ ÁLVAREZ DE SOTOMAYOR, S., Viajes combinados y servicios de viaje vinculados [Directiva (UE) 2015/2302] Cuestiones de ley aplicable, Madrid, Reus, 2018, pp. 18-19.

${ }^{6}$ BOE núm. 312, de 27 de diciembre. El Real Decreto-ley fue convalidado por el Congreso de los Diputados el 22 de enero de 2019 (BOE núm. 25, de 29 de enero de 2019).

${ }^{7}$ Tras la incorporación de la Directiva 2015/2302, los viajes combinados siguen estando regulados en la norma general de protección de los consumidores, aun cuando - como se verá más adelante- el viajero (sujeto protegido) podrá ser una persona que no ostente la condición de consumidor. Sobre el proceso de incorporación de las disposiciones de la Directiva a nuestro Ordenamiento vid. ZUBIRI MARTÍNEZ DE SALINAS, M., "La reforma de la LGDCU para adaptar el Derecho español a la Directiva (UE) 2015/2302 del Parlamento Europeo y del Consejo, de 25 de noviembre de 2015, relativa a los viajes combinados y a los servicios de viaje vinculados", en 
Entre los objetivos principales perseguidos por la nueva Directiva se encuentran el de elevar el nivel de protección de los viajeros y el de evitar distorsiones en la competencia, ocasionadas estas últimas por la actividad de los operadores (fundamentalmente aerolíneas) que ofrecían de hecho viajes combinados y a los que no se les aplicaba la Primera Directiva sobre viajes combinados ${ }^{8}$.

El aumento de la protección de los viajeros presenta una triple vertiente. En primer lugar, se amplía el concepto de viaje combinado para incluir todas aquellas combinaciones que, por su apariencia, crean en el viajero la impresión legítima de estar contratando un viaje combinado y no servicios sueltos ${ }^{9}$. En segundo lugar, se regulan los servicios de viaje vinculados, como figura "puente" entre los viajes combinados y los servicios de viajes sueltos. Como ya se adelantó, los servicios de viaje vinculados son combinaciones de servicios de viaje que no pueden conceptuarse como viajes combinados, pero que presentan algún elemento que los diferencian de la contratación de servicios sueltos y, por tanto, merecen cierta protección, aun cuando esta sea menor de la que se ofrece al viajero en el viaje combinado. Por último, se establecen deberes de información destinados específicamente a advertir al viajero sobre el tipo de contrato que está realizando, dado el distinto nivel de protección que ofrecen los viajes combinados y los servicios de viaje vinculados.

Por lo que respecta a la ampliación del concepto de viaje combinado, la práctica del sector turístico y la doctrina ha denominado "paquete dinámico" a todas estas nuevas combinaciones de servicios turísticos en las que el viajero interviene, de forma más o menos intensa, en la confección del mismo. Los “paquetes dinámicos” se caracterizan ${ }^{10}$, en primer lugar, por ser un

El nuevo régimen de los viajes combinados y servicios de viaje vinculados en el Derecho español, Valencia, Tirant lo Blanch, 2020 (edición digital), pp. 25-30.

\footnotetext{
${ }^{8}$ Se pretende, además, poner fin a la fragmentación jurídica que había generado la Directiva 90/314, y al aumento de costes que dicha situación provocaba en los empresarios que deseaban llevar a cabo actividades transfronterizas, todo ello en perjuicio de los consumidores (Considerando 4 de la Directiva 2015/2302).

${ }^{9}$ Sobre la ampliación del concepto de viaje combinado en la nueva regulación y su caracterización actual vid. el detenido análisis realizado por GONZÁLEZ FERNÁNDEZ, M.B., en su trabajo "Redefiniciones y armonización en materia de viajes combinados", op. cit., II. Resulta en este punto muy clarificador el empleo en los documentos preparatorios de la Directiva 2015/2302, así como en la Propuesta de Directiva [Propuesta de Directiva del Parlamento Europeo y del Consejo relativa a los viajes combinados y los servicios asistidos de viaje, por la que se modifican el Reglamento (CE) $\mathrm{n}^{\circ} 2006 / 2004$ y la Directiva 2011/83/UE y por la que se deroga la Directiva 90/314/CEE, Bruselas 9.7.2013 COM(2013) 512 final] y en el texto finalmente aprobado, de términos tales como "asociación", "semejanza", "percepción del consumidor" para referirse a estas nuevas combinaciones, tanto en lo relativo a su configuración como a la impresión que causan en el viajero.
}

${ }^{10}$ Vid. LONDON ECONOMICS, Study on Consumer Detriment in the area of Dinamic Packages, Final report to the European Commission - Health and Consumers DG, November 2009, pp. 4-5 (disponible en https://leeurope.eu/publication/study-on-consumer-detriment-in-the-area-of-dynamic-packages/); $\quad$ APARICIO VAQUERO, J.P. - BATUECAS CALETRIO, A., "Régimen de responsabilidad en la prestación de servicios turísticos contratados como paquetes dinámicos", en Paquetes dinámicos: problemas y soluciones jurídicas desde una perspectiva internacional (dir. Paniza Fullana, A.), Madrid, Dykinson, 2014 (edición digital), pp. 57-58; CAMARGO GÓMEZ, J.D., "Contratación electrónica de paquetes dinámicos de turismo en el ordenamiento jurídico español”, Ars Iuris Salmanticensis, vol. 2, 2014, pp. 100 y ss. 
"paquete", lo que implica que incluyen dos o más servicios turísticos, que esos servicios se han adquirido del mismo proveedor (o, si son varios proveedores, están comercialmente relacionados) y que los distintos servicios se adquieren (contratan) al mismo tiempo. En segundo lugar, se trata de un paquete "dinámico", en el sentido de que es ensamblado por el viajero que decide qué servicios incluye y cuáles no. Los paquetes dinámicos se clasifican en unitary packages y derivative packages. En el primer caso, los servicios de viaje se contratan en una sola página web, mientras que en el segundo supuesto la contratación se realiza por medio de páginas webs enlazadas ${ }^{11}$.

No obstante, la Directiva 2015/2302 ha optado por no utilizar la expresión "paquete dinámico"12 $\mathrm{y}$, en su lugar, amplia el concepto de viaje combinado y regula la nueva figura de los servicios de viaje vinculados. De esta manera, los denominados "paquetes dinámicos" quedan subsumidos en las dos figuras legalmente previstas: serán calificados como viajes combinados o como servicios de viaje vinculados ${ }^{13}$.

\section{DEFINICIÓN Y CARACTERÍSTICAS DE LOS SERVICIOS DE VIAJES VINCULADOS}

La regulación de los servicios de viaje vinculados se encuentra recogida en los artículos 151.1.e), 167 y 168 del Libro IV del TRLGDCU, si bien hay que recurrir a otros preceptos del Libro IV para completar su régimen jurídico (definiciones, responsabilidad por errores en la reserva, constitución de garantía frente a la insolvencia, etc.).

El artículo 151.1.e) del TRLGDCU define los servicios de viaje vinculados como "al menos dos tipos diferentes de servicios de viaje adquiridos con objeto del mismo viaje o vacación, que, sin constituir un viaje combinado, den lugar a la celebración de contratos distintos con cada uno de los prestadores individuales de servicios de viaje, si un empresario facilita: a) con ocasión de una única visita o contacto con su punto de venta, la selección y el pago separado de cada servicio de viaje por parte de los viajeros, o b) de manera específica, la contratación de al menos un servicio de viaje adicional con otro empresario, siempre que tenga lugar a más tardar 24 horas después de la confirmación de la reserva del primer servicio de viaje".

Resulta un tanto extraño que el precepto no utilice un sustantivo para definir los servicios de viaje vinculados. En efecto, mientras que el viaje combinado es "la combinación de, al menos,

\footnotetext{
${ }^{11}$ Vid. PANIZA FULLANA, A., Viajes combinados y servicios de viaje vinculados..., op. cit., p. 23; GONZÁLEZ CABRERA, I., "El contrato de viaje combinado y los paquetes dinámicos (servicios de viaje vinculados), en Manual de contratación turística (dir. Franch Fluxá, J.), Barcelona, Atelier, 2019, p. 149.

${ }^{12}$ Vid. ZUBIRI MARTÍNEZ DE SALINAS, M., "Los nuevos conceptos en materia de viajes combinados y servicios de viaje vinculados", en El nuevo régimen de los viajes combinados y servicios de viaje vinculados en el Derecho español, Valencia, Tirant lo Blanch, 2020 (edición digital), p. 62, nota núm. 18.

${ }^{13}$ Vid. PEINADO GRACIA, J.I., "La protección del pasajero...”, op. cit., p. 524; PANIZA FULLANA, A., Viajes combinados y servicios de viaje vinculados..., op. cit., p. 50.
} 
dos tipos de servicios de viaje..." [art. 151.1.b)], los servicios de viaje vinculados son "al menos dos tipos diferentes de servicios de viaje...”. Aunque quizás se quiera evitar la utilización del término "combinación" para no inducir a error con los viajes combinados, entendemos que es oportuno calificar a los servicios de viaje vinculados como "combinación de distintos servicios de viaje", dejando claro posteriormente que se trata de combinaciones que no dan lugar a viajes combinados $^{14}$. De hecho, la propia norma emplea este término en alguna ocasión con relación a los servicios de viaje vinculados [art. 151.1.e) TRLGDCU] y lo hacía también la Propuesta de Directiva al definir en su artículo $3^{\circ} 5$ ) el servicio asistido de viaje (que era como se denominaron inicialmente los servicios de viaje vinculados) como "la combinación de al menos dos tipos diferentes de servicios de viaje para el mismo viaje o vacación que no constituya un viaje combinado y que dé lugar a la celebración de contratos separados con cada uno de los proveedores de servicios de viaje, si un minorista facilita la combinación".

De la definición ofrecida por el artículo 151.1.e) TRLGDCU se extraen las siguientes características de los servicios de viaje vinculados ${ }^{15}: 1^{\text {a }}$ ) consisten en la combinación de al menos dos tipos diferentes de servicios de viaje para el mismo viaje o vacación; $2^{\mathrm{a}}$ ) la combinación no constituye un viaje combinado; $3^{\mathrm{a}}$ ) el viajero celebra distintos contratos con cada prestador de servicios de viaje; $4^{\mathrm{a}}$ ) para que se produzca la vinculación se requiere que los contratos se celebren al mismo tiempo -o en un lapso corto de tiempo- (requisito temporal) y la labor "facilitadora" de un empresario en la forma legalmente prevista. Debe tenerse en cuenta, no obstante, que las características primera y tercera no son exclusivas de los servicios de viaje

\footnotetext{
${ }^{14}$ En este sentido señala ZUBIRI MARTÍNEZ DE SALINAS ("Los nuevos conceptos en materia de viajes combinados...", op., cit., p. 55) que el elemento común de ambos (viajes combinados y servicios de viaje vinculados) es la combinación al menos de dos servicios de viaje e incluso propone encuadrar a ambos en una categoría común que, indica, podría denominarse "servicios turísticos combinados" (vid., de la misma autora y obra, p. 63).

${ }^{15}$ Vid. DEPARTMENT FOR BUSINESS, ENERGY \& INDUSTRIAL STRATEGY, The Package Travel and Linked Travel Arrangements Regulations 2018. Guidance for businesses, United Kingdom, March, 2021, p. 22 (disponible https://assets.publishing.service.gov.uk/government/uploads/system/uploads/attachment_data/file/967428/packa ge-travel-and-linked-travel-arrangements-regulations-2018.pdf.). La transposición de la Directiva 2015/2302 al Ordenamiento de Reino Unido se llevó a cabo mediante The Package Travel and Linked Travel Arrangements Regulations (PTRs 2018, Statutary Instruments 2018 N 634).
} 


\begin{abstract}
vinculados, ya que están (primera característica) ${ }^{16}$ o pueden estar (tercera característica $)^{17}$ presentes en los viajes combinados.
\end{abstract}

El artículo 150 TRLGDC contempla una serie de supuestos a los que, a pesar de que la combinación se califique como viaje combinado o como servicios de viaje vinculados de conformidad con lo previsto en artículo 151.1, apartados b) y e), no se les aplicará el régimen establecido para aquéllos. Se trata de viajes combinados y servicios de viaje vinculados de duración inferior a veinticuatro horas, a menos que se incluya el alojamiento ${ }^{18}$; viajes combinados y servicios de viaje vinculados que se faciliten de manera ocasional, sin ánimo de lucro y únicamente a un reducido grupo de personas $^{19}$; y viajes combinados y servicios de viaje

\begin{abstract}
${ }^{16}$ Así, como se ha señalado, el viaje combinado se define como "la combinación de, al menos, dos tipos de servicios de viaje a efectos del mismo viaje o vacación..." [art. 151.1.b) TRLGDCU]. Puede observarse que para el viaje combinado no se exige que los tipos de servicios de viaje sean "diferentes", al contrario de lo que sucede con los servicios de viaje vinculados. No obstante, entendemos que es presupuesto para la existencia de ambas clases de combinaciones (viajes combinados y servicios de viaje vinculados) que los servicios de viaje pertenezcan a distintas categorías (transporte, alojamiento, etc.). Y ello es así porque el artículo 151.1.b) no habla de la combinación de al menos "dos servicios de viaje" sino de al menos "dos tipos de servicios de viaje", por lo que, entendemos, el hecho de que el artículo 151.1.e) exija que los tipos sean diferentes no añade nada. En este contexto, el hecho de que el término apuntado no aparezca en la definición de viaje combinado y sí en la de servicios de viaje vinculados puede deberse a un olvido del legislador y no a la intención de establecer en este aspecto diferencias entre ambos tipos de combinaciones. Así, la versión en inglés de la Directiva 2015/2302 establece en su artículo $3^{\circ}$ 2) lo siguiente: "package means a combination of at least two different types of travel services for the purpose of the same trip or holiday, if..." (el subrayado es nuestro).
\end{abstract}

${ }^{17}$ El artículo 151.1.b) TRLGDCU diferencia, dentro de los viajes combinados, dos supuestos distintos según que se celebre un único contrato por la totalidad de los servicios de viaje o varios contratos con los prestadores de los servicios de viaje.

${ }^{18}$ La exclusión obedece a que en los viajes de corta duración la necesidad de proteger a los viajeros es menor y por tanto no deben imponerse cargas innecesarias a los empresarios (cfr. Considerando 19 Directiva 2015/2302). Sobre la posibilidad de que los Estados miembros apliquen las disposiciones de la Directiva a los servicios de viaje vinculados de duración inferior a veinticuatro horas que no incluyan alojamiento vid. Considerando 21 Directiva 2015/2302. Con respecto al empleo del término "alojamiento" en lugar de "pernoctación" -empleado este último en la Directiva 2015/2302-, vid. ZUBIRI MARTÍNEZ DE SALINAS, M., "La reforma de la LGDCU para adaptar el Derecho español a la Directiva (UE) 2015/2302...", op. cit., p. 41, nota núm. 20; ZUBIRI MARTÍNEZ DE SALINAS, M., "Los nuevos conceptos en materia de viajes combinados..., op., cit., p. 66.

${ }^{19}$ Se trata de requisitos cumulativos no alternativos. Con respecto a la ausencia de ánimo de lucro, se ha indicado que se cumple este requisito cuando las cantidades pagadas únicamente cubren los costes en los que se ha incurrido, o bien el beneficio es marginal y se dedica a fines caritativos o humanitarios [vid. COMISIÓN EUROPEA, Transposition of Directive (EU) No 2015/2302 on Package Travel and Linked Travel Arrangements Workshop with Member States on 13 June 2016, p. 14; los documentos que recogen las cuestiones analizadas en los sucesivos workshops celebrados están disponibles en https://ec.europa.eu/newsroom/just/item-detail.cfm?item_id=35324]. La exigencia de que los servicios de viaje se faciliten a un grupo reducido de personas puede entenderse cumplida cuando los servicios de viaje vinculados no se ofrezcan al público en general. Por su parte, el Considerando 19 de la Directiva 2015/2302 entiende que el viaje será "ocasional" cuando se organicen como mucho "unas cuantas veces al año" y pone como ejemplos los viajes organizados por una organización benéfica, un club deportivo o un colegio para sus miembros. La exención se aplicaría cuando el club deportivo, organización benéfica o colegio actúan como facilitadores u organizadores, pero no cuando aquellos acuden a un organizador-facilitador profesional. Sobre la posibilidad de que los Estados miembros apliquen las disposiciones de la Directiva a los servicios de viaje vinculados que se faciliten sin ánimo de lucro para un número limitado de viajeros y únicamente de modo ocasional vid. Considerando 21 de la Directiva. 
vinculados contratados sobre la base de un convenio general para la organización de viajes de negocios. En este último caso se entiende que quien ha celebrado el convenio con el empresario que ofrece los viajes combinados y los servicios de viaje vinculados tendrá un poder de negociación suficiente que le permita plasmar en el convenio unas condiciones especiales y, por tanto, los viajes combinados y los servicios de viaje vinculados contratados al amparo de este convenio no necesitan de la protección que ofrece la norma ${ }^{20}$.

La definición ofrecida permite, además, delimitar las partes que intervienen en los servicios de viaje vinculados ${ }^{21}$ : el viajero, el empresario que facilita la contratación de distintos servicios de viaje y los prestadores de servicios de viaje (compañía aérea, hotel, etc.).

La noción de viajero es más amplia que la de consumidor, al incluir a los viajeros de negocios, entendiendo por tales los que contratan servicios de viaje por motivos de su actividad comercial, negocio, oficio o profesión, siempre que los contratos no estén amparados por un convenio general para la organización de viajes de negocios ${ }^{22}$. La inclusión de los viajeros de negocios en el ámbito de aplicación de la norma obedece a que éstos utilizan los mismos canales de reserva que los turistas - esto es, quien viaje por motivos de ocio- $y$, por tanto, requieren un nivel de protección $\operatorname{similar}^{23}$.

Los empresarios que facilitan servicios de viaje vinculados pueden ser tanto intermediarios agencias de viaje -físicas u on line $e^{24}$ y centrales de reserva ${ }^{25}$ como prestadores de servicios de viaje. No serían, sin embargo, empresarios facilitadores los metabuscadores, que actuarían

20 Vid. PEINADO GRACIA, J.I., "La protección del pasajero...”, op. cit., pp. 531-532; BERENGUER ALBALADEJO, C., "Luces y sombras de la nueva Directiva...”, op. cit., p. 43.

${ }^{21}$ Es preferible, en nuestra opinión, no emplear la expresión "partes del contrato” ya que, en puridad, no existe un contrato de servicios de viaje vinculados.

${ }^{22}$ Vid. arts. 150.2.c) y 151.1.f) TRLGDCU y Considerando 7 de la Directiva 2015/2302. Sobre el concepto de viajero en la nueva regulación vid., más ampliamente, ZUBIRI MARTÍNEZ DE SALINAS, M., "Los nuevos conceptos en materia de viajes combinados...", op., cit., pp. 82-85.

${ }^{23}$ Vid. Considerando 7 de la Directiva 2015/2302; DEPARTMENT FOR BUSINESS, ENERGY \& INDUSTRIAL STRATEGY, The Package Travel and Linked Travel..., op. cit., p. 6; BATUECAS CALETRIO, A., "La contratación de viajes vinculados", op., cit., pp. 6-7. Sobre la aplicación de la normativa sobre viajes combinados a los viajeros de negocios en la anterior regulación vid. FERRER TAPIA, B., “Aspectos subjetivos de los paquetes dinámicos. La situación del consumidor”, en Paquetes dinámicos: problemas y soluciones jurídicas desde una perspectiva internacional (dir. Paniza Fullana, A.), Madrid, Dykinson, 2014 (edición digital), p. 36 y, más ampliamente, el análisis realizado por ZUBIRI DE SALINAS, M., "Conceptos clave y responsabilidad en la nueva regulación de los viajes combinados y los servicios de viaje vinculados", Revista europea de derecho de la navegación marítima y aeronáutica, núm. 34, 2017 (edición digital), pp. 6 y ss.

${ }^{24}$ OTA, por sus siglas en inglés (Online Traveller Agency).

${ }^{25}$ Sobre la naturaleza de las centrales de reserva vid. MARTÍNEZ NADAL, A., "Las centrales electrónicas de reservas turísticas: breves consideraciones acerca de su naturaleza y régimen jurídico", en Estudios de Derecho mercantil. Libro homenaje al Prof. Dr. H.c. José Antonio Gómez Segade (coord. Tobío Rivas, A.M.), Madrid, Marcial Pons, 2013, pp. 967-984. 
como proveedores de enlaces, quedando su actividad sometida a lo previsto en la Ley de Servicios de la Sociedad de la Información y de Comercio Electrónico (en adelante, LSSICE) ${ }^{26}$.

Procedemos seguidamente al análisis de las características de los servicios de viaje vinculados.

\subsection{Combinación del al menos dos tipos diferentes de servicios de viaje para el mismo viaje o vacación}

Los servicios de viaje que pueden dar lugar a la formación de servicios de viaje vinculados son los mismos que los que pueden integrar el viaje combinado y se agrupan en dos categorías, a las que denominaremos servicios de viaje principales y servicios de viaje secundarios. Los servicios de viaje principales serían el transporte de pasajeros, el alojamiento -cuando no sea parte integrante del transporte ${ }^{27}$ ni tenga un fin residencial ${ }^{28}$ - y el alquiler de vehículos de motor $^{29}$. Los servicios de viaje secundarios son servicios turísticos distintos de los anteriores que no son parte integrante de un servicio de viaje principal $^{30}$ : entradas a conciertos o

\footnotetext{
${ }^{26}$ Vid. BATUECAS CALETRIO, A., "La contratación de viajes vinculados”, op ., cit., p. 7 y nota núm. 18. Sobre las funciones y naturaleza de los metabuscadores en el ámbito de los servicios turísticos vid. BATUECAS CALETRIO, A. - APARICIO VAQUERO, J.P., "La contratación on line de servicios turísticos", en Nuevas fórmulas de contratación on line de servicios turísticos: subsunción en los tipos legales y distribución de responsabilidad (coord. Paniza Fullana, A.), Granada, Comares, 2013, pp. 55-56.

${ }^{27}$ Por ejemplo, el viaje en tren en un coche cama, en el que la finalidad del viaje es desplazarse de un lugar a otro y la pernoctación es necesaria para el desplazamiento (vid., en este sentido, el Considerando 17 de la Directiva 2015/2302).

${ }^{28}$ Aclara el Considerando 17 de la Directiva 2015/2302 que el alojamiento para cursos de idiomas de larga duración se equipara al alojamiento con fin residencial, por lo que no sería calificado de alojamiento (y, por tanto, de servicio de viaje). No aclara la norma, sin embargo, qué debe entenderse por "larga duración" a efectos de la exclusión. El mismo Considerando añade que tampoco serían servicios de viaje los servicios financieros como los seguros de viaje. Por lo que respecta a los alquileres de viviendas turísticas, compartimos la opinión de quienes entienden que deben quedar incluidos en el concepto de alojamiento (vid., en este sentido, ZUBIRI DE SALINAS, M., "Conceptos clave y responsabilidad...",op. cit., p. 4, nota núm. 7; la misma opinión parece compartir PANIZA FULLANA, A., en Viajes combinados y servicios de viaje vinculados..., op. cit., pp. 42-43).
}

${ }^{29}$ Sobre la calificación del alquiler de vehículos de motor como servicio de viaje equiparado en la nueva regulación al transporte y al alojamiento vid., con una visión crítica, PEINADO GRACIA, J.I., "La protección del pasajero...", op. cit., p. 525, nota núm. 43.

${ }^{30}$ En el Considerando 17 de la Directiva se citan varios ejemplos de servicios turísticos que, por quedar integrados en un servicio de viaje principal, no deben considerarse servicios de viaje en sí mismos. Son, por ejemplo, "el transporte de equipaje realizado como parte del transporte de viajeros; pequeños servicios de transporte, como el traslado de los pasajeros como parte de una visita guiada o los traslados entre un hotel y un aeropuerto o estación de ferrocarril; las comidas, las bebidas y los servicios de limpieza facilitados como parte del servicio de alojamiento; o el acceso a instalaciones del hotel como piscinas, saunas, balnearios o gimnasios incluidos en el alojamiento para los viajeros alojados en el hotel". Se ha señalado (vid. BATUECAS CALETRIO, A., "La contratación de viajes vinculados", op. cit., p. 9) que debe entenderse que un servicio de viaje forma parte intrínseca de otro cuando el primero no tiene sentido por sí mismo, ya que es prestado en relación directa con aquél. 
acontecimientos deportivos, excursiones o parques de atracciones, visitas guiadas, forfaits de esquí, alquiler de material deportivo, tratamientos en balnearios, etc. ${ }^{31}$

La lista de los servicios de viaje principales debe considerarse cerrada; es decir, a los efectos de aplicar el régimen previsto en la norma, no existen más servicios de viaje principales que los que ella menciona. Por lo que respecta a los servicios de viaje secundarios, el legislador ha optado por no definirlos ni enumerarlos; señala simplemente que se trata de cualquier otro servicio turístico distinto de los calificados como principales. Adicionalmente, la exigencia de que se combinen "al menos dos tipos diferentes de servicios de viaje" implica que los servicios de viaje que se ensamblan deben pertenecer al menos a dos categorías distintas, de forma que, por ejemplo, la combinación de dos transportes - ni aun cuando se trate de transportes distintosno es una combinación apta para formar servicios de viaje vinculados ${ }^{32}$.

La contratación de servicios de viaje secundarios presenta peculiaridades en orden a determinar si su combinación da lugar o no a la formación de servicios de viaje vinculados. En primer lugar, si únicamente se contratan servicios de viaje secundarios no se está ante unos servicios de viaje vinculados porque se trataría de servicios de viaje "del mismo tipo". Dicho en otros términos, el requisito de la combinación de dos o más servicios de viaje exige que al menos uno de ellos sea un servicio de viaje principal ${ }^{33}$. En segundo lugar, deben diferenciarse los supuestos en los que el viajero contrata dos o más servicios de viaje principales y uno o varios servicios de viaje secundarios (por ejemplo, transporte, alojamiento y entrada para un concierto) de aquellos otros en los que adquiere un solo servicio de viaje principal con uno o más servicios de viaje secundarios (alojamiento y entrada para un concierto).

Si se contratan dos o más servicios de viaje principales y uno o más servicios de viaje secundarios, la norma no exige ningún requisito adicional para entender que existe la combinación. Por el contrario, si se contrata un solo servicio de viaje principal con uno o más servicios de viaje secundarios (por ejemplo, hotel más entrada a un concierto), los servicios de viaje vinculados únicamente se formarán si $a$ ) el valor del servicio de viaje o servicios de viaje secundarios es igual o superior al veinticinco por ciento del valor de la combinación ${ }^{34} \mathrm{o}$ (es

\footnotetext{
${ }^{31}$ Vid. Considerando 18 de la Directiva 2015/2302.

32 BATUECAS CALETRIO ("La contratación de viajes vinculados", op. cit., pp. 10-11), tras señalar que esta es la interpretación que debe realizarse del tenor literal del precepto, entiende que la combinación de servicios de viaje de la misma naturaleza (tipo) no debería haberse excluido del ámbito de aplicación de la Directiva. Sobre esta cuestión vid. también ZUBIRI MARTÍNEZ DE SALINAS, M., "Los nuevos conceptos en materia de viajes combinados...", op., cit., pp. 66-67. El Sistema de Reservas eSky ofrece un servicio de combinaciones de vuelos, advirtiendo de que no se trata de un billete combinado (vid. Términos y Condiciones. 9. Servicio MultiLine, accesible en https://www.esky.es/terminos-y-condiciones, consultada el 19 de marzo de 2021).

${ }^{33}$ En este sentido vid. MARTÍNEZ ESPÍN, P., "La reforma del régimen de los viajes combinados y servicios de viaje vinculados", LA LEY mercantil, núm. 55, 2019 (edición digital), p. 5.

${ }^{34}$ La Directiva 2015/2302 establece en su articulado que los servicios de viaje secundarios deben representar una "proporción significativa del valor combinado de los servicios", sin fijar concretamente el porcentaje. No obstante, el Considerando 18 sí hace referencia al porcentaje del veinticinco por ciento, al señalar que "(S)i otros servicios
} 
decir, no obstante no alcanzar ese veinticinco por ciento), $b$ ) el servicio o los servicios de viaje secundarios se han anunciado como elemento esencial del viaje o vacación o constituyen por alguna otra razón (es decir, por una razón distinta a su valor) una característica esencial del viaje o vacación ${ }^{35}$. De lo expuesto se deduce que lo relevante para determinar si en estos casos estamos o no en presencia de servicios de viaje vinculados es que el servicio de viaje secundario sea una característica esencial de la combinación, presumiéndose que lo es cuando su valor sea igual o superior al veinticinco por ciento del valor de la combinación (si hay varios servicios de viaje secundarios, el cálculo del porcentaje tendrá en cuenta la suma del valor de todos ellos). Ahora bien, si los servicios de viaje secundarios se han anunciado como un "elemento esencial" del viaje, la apariencia generada por el anuncio hace que no haya de investigarse la naturaleza esencial o no del viaje secundario (puede ocurrir de esta manera que servicios de viaje secundarios que por naturaleza no sean esenciales en una combinación, pasen a serlo por el solo hecho de que quien oferta los servicios de viaje vinculados así lo anuncie). El problema reside en si el viajero tiene conocimiento de que, precisamente, por no cumplir los requisitos señalados, la combinación que contrata no va a adquirir la condición de servicios de viaje vinculados ${ }^{36}$.

turísticos representan el 25\% o más de la combinación, debe considerarse que constituyen una proporción significativa del valor del viaje combinado o del de los servicios de viaje vinculados" [la Propuesta de Directiva fijaba el porcentaje en el veinte por ciento (vid. Considerando 17)]. En respuesta a una pregunta planteada, la Comisión indicó que el criterio del veinticinco por ciento recogido en el Considerando 18 de la Directiva podía incluirse en las normas nacionales de trasposición, añadiendo así claridad y transparencia (vid. COMISIÓN EUROPEA, Workshop with Member States on 13 June 2016, op. cit., p. 13). Se ha advertido (DEPARTMENT FOR BUSINESS, ENERGY \& INDUSTRIAL STRATEGY, The Package Travel and Linked Travel..., op. cit., pp. 7-8) del peligro de que se eleve artificialmente el precio del servicio de viaje principal y se reduzca de la misma forma el precio de los servicios secundarios, al objeto de que éstos no alcancen la proporción señalada. La Comisión ha señalado al respecto [vid. Transposition of Directive (EU) No 2015/2302 on Package Travel and Linked Travel Arrangements Workshop with Member States on 25 October 2016] que en estos casos deberá atenderse al valor intrínseco de los servicios y no al precio pagado por ellos. Por otro lado, la Comisión Nacional de los Mercados y la Competencia (en adelante, CNMC), en su Informe sobre el Anteproyecto de Ley por la que se modifica el Texto Refundido de la Ley General para la Defensa de los Consumidores y Usuarios y otras Leyes complementarias, de 21 de diciembre de 2017 (IPN/CNMC/042/17), recomendaba que se justificara por qué se había elegido el porcentaje del veinticinco por ciento, al tratarse de una cuestión relevante pues de ese umbral dependía la exclusión de determinadas combinaciones como viaje combinados o servicios de viaje vinculados (vid. p. 10). El Informe está disponible en https://www.cnmc.es/sites/default/files/1887234_5.pdf.

${ }^{35}$ Art. 151.1.e): “(C)uando se adquiera como máximo uno de los servicios de viaje a que se refieren los apartados $1^{\circ}, 2^{\circ}$ o $3^{\circ}$ de la letra a) y uno varios de los servicios turísticos a que se refiere su apartado $4^{\circ}$, no constituirán servicios de viaje vinculados si estos últimos no representan una proporción igual o superior al veinticinco por ciento de la combinación y no se anuncian o no constituyen por alguna otra razón una característica esencial de la combinación". Se observa un defecto en la redacción del artículo, ya que donde dice "y no se anuncian" debe decir "o no se anuncian". El error puede obedecer a la transcripción literal de lo dispuesto en el artículo $3^{\circ}$ de la Directiva 2015/2302 (como apoyo a la interpretación que se ha dado a este precepto en el texto vid. Considerando 18 de la Directiva; BATUECAS CALETRIO, A., "La contratación de viajes vinculados", op. cit., pp. 9-10; BERENGUER ALBALADEJO, C., "Luces y sombras de la nueva Directiva...”, op. cit., pp. 39-40).

${ }^{36}$ El Informe de la CNMC sobre el Anteproyecto de Ley de transposición de la Directiva (vid. Informe de la CNMC sobre el Anteproyecto de Ley..., op. cit., p. 9) incidía sobre esta cuestión, recomendando que se informara con claridad a los consumidores de esta circunstancia para que pudieran adoptar la decisión más adecuada a sus intereses. 
Por lo demás, el precepto exige que los servicios de viaje se contraten para "un mismo viaje o vacación". La precisión es importante ya puede ocurrir que se contraten diversos servicios de viaje en un mismo momento (lo que, como vimos, en una característica de los paquetes dinámicos) pero si no son para el mismo viaje o vacación no se formarán los servicios de viaje vinculados ${ }^{37}$.

\subsection{La combinación no constituye un viaje combinado}

Este requisito, que la versión en español de la Directiva 2015/2302 omite (sí aparece, por el contrario, en la versión en inglés), implica que para que una combinación de servicios de viaje pueda ser calificada de servicios de viaje vinculados previamente debe descartarse que se trate de un viaje combinado ${ }^{38}$. El Real Decreto-ley 23/2018 sí recoge esta exigencia, de forma acertada en nuestra opinión, ya que, ciertamente, los servicios de viaje vinculados no se parecen al que podríamos denominar "viaje combinado tradicional", en el que se da una combinación de servicios de viaje preestablecida por el organizador ${ }^{39}$, pero sí presentan similitudes con algunas de las combinaciones que, tras la ampliación del concepto operada por la Directiva $2015 / 2302$, constituyen viajes combinados. Se hace, por tanto, necesario aclarar, que en caso de que una combinación pueda calificarse de viaje combinado y servicio de viaje vinculado, prevalecerá la primera por ser más tuitiva para el viajero.

$Y$ es que, en efecto, el TRLGDCU entiende que existe viaje combinado, aun cuando no se celebre un único contrato, cuando los servicios de viaje: a) son contratados en un único punto de venta y seleccionados antes de que el viajero acepte pagar (por ejemplo, se contratan los servicios de viaje en una web y se acumulan distintos servicios de viaje en una cesta de compra virtual) ${ }^{40}$; b) son ofrecidos, vendidos o facturados a un precio a tanto alzado o global (por ejemplo, vuelo+hotel); c) son anunciados o vendidos como "viaje combinado" o bajo una denominación similar (oferta combinada, todo incluido, paquete turístico vacacional); d) son

\footnotetext{
${ }^{37}$ Vid. COMISIÓN EUROPEA, Workshop with Member States on 25 October 2016, op., cit., p. 9.

${ }^{38}$ Vid. DEPARTMENT FOR BUSINESS, ENERGY \& INDUSTRIAL STRATEGY, The Package Travel and Linked Travel..., op. cit., p. 22.

${ }^{39}$ Según el actual artículo 151.1.b) $1^{\text {o }}$ TRLGDCU existe viaje combinado cuando "los servicios de viaje son combinados por un solo empresario, incluso a petición o según la selección del viajero, antes de que se celebre un único contrato por la totalidad de los servicios”. Puede observarse que, en línea con las interpretaciones judiciales y con la opinión de una relevante doctrina, la definición incluye no solo las combinaciones preestablecidas por el empresario, sino también aquellas en las que es el viajero quien selecciona los servicios de viaje que integran la combinación que dé lugar a la celebración de un único contrato. Sobre esta cuestión vid. más ampliamente CAMARGO GÓMEZ, J.D., “Contratación electrónica de paquetes dinámicos...”, op. cit., pp. 104-107; PEINADO GRACIA, J.I., "La protección del pasajero en el contrato de viaje combinado y en la prestación de servicios asistidos de viaje...", op. cit., pp. 526-527.

${ }^{40}$ Podría decirse que lo característico de este supuesto es que existe un único procedimiento de reserva. Como se ha señalado, la expresión "acepte pagar" puede coincidir con la asunción de la obligación de pagar (casos en los que se posponga el pago) como con un pago inmediato tras la selección de los servicios de viaje (vid. DEPARTMENT FOR BUSINESS, ENERGY \& INDUSTRIAL STRATEGY, The Package Travel and Linked Travel..., op. cit., p. 9).
} 
combinados después de la celebración de un contrato en virtud del cual el empresario permite al viajero elegir entre una selección de distintos tipos de servicios de viaje (caja regalo) ${ }^{41}$; o e) son contratados con distintos empresarios a través de procesos de reserva en línea conectados en los que el nombre del viajero, sus datos de pago y su dirección de correo electrónico son transmitidos por el empresario con el que se celebra el primer contrato a otro u otros empresarios con quienes se celebra otro contrato, a más tardar veinticuatro horas después de la confirmación de la reserva del primer servicio de viaje (contratación de servicios de viaje a través de páginas webs enlazadas $)^{42}$.

Aparentemente, los supuestos que pueden generar confusión con los servicios de viaje vinculados serían los contemplados en los apartados a) y e). Ahora bien, también es posible que los servicios de viaje se anuncien como un viaje combinado, todo incluido o similar (apartado c) pero luego la contratación se realice en alguna de las formas previstas para los servicios de viaje vinculados. Lo que quiere decir la norma es que, en estos casos, la calificación que proceda será la de viaje combinado y no la de servicios de viaje vinculados.

El discernimiento sobre la naturaleza de la combinación -viaje combinado o servicios de viaje vinculados- recae sobre el empresario, ya que uno de los deberes que le incuben es, precisamente, informar al viajero sobre el tipo de viaje que está contratando ${ }^{43}$. El articulo 150.3 TRLGDCU da a entender que la calificación que realiza el empresario debe ajustarse a la realidad, ya que aun cuando declare que los servicios que se prestan no constituyen un viaje combinado o servicios de viaje vinculados, esto no le eximirá de sus obligaciones ${ }^{44}$.

\subsection{El viajero contrata los servicios de viaje con cada prestador de servicios de viaje}

Como se señaló anteriormente, en los servicios de viaje vinculados el viajero celebra distintos contratos con cada uno de los prestadores de servicios de viaje. Cada uno de ellos es responsable de la prestación del servicio de viaje al que se ha obligado, no asumiendo el empresario facilitador ninguna obligación por la no ejecución o la ejecución defectuosa de los servicios de

\footnotetext{
${ }^{41}$ En relación con las “cajas regalo” vid. ZUBIRI MARTÍNEZ DE SALINAS, M., "Los nuevos conceptos en materia de viajes combinados..., op. cit., pp. 60-61.

${ }^{42}$ Sobre el último supuesto mencionado indica GONZÁLEZ FERNÁNDEZ ("Redefiniciones y armonización en materia de viajes combinados", op. cit., II.1.1) que se trata "de datos que permiten concluir una reserva con el cliente, no bastando que se transfiera simplemente la información sobre su destino o las fechas en las realizará el viaje". De transmitirse únicamente el destino o las fechas en que el viaje tendrá lugar, la combinación podría calificarse de servicios de viaje vinculados si se cumplen los demás requisitos que exige el artículo 151.1.e) TRLGDCU.

${ }^{43}$ Vid. PANIZA FULLANA, A., Viajes combinados y servicios de viaje vinculados..., op. cit., p. 115.

${ }^{44}$ Art. 150.3 TRLGDCU: "No quedarán eximidos de las obligaciones establecidas en este libro los organizadores de viajes combinados, o, en su caso, los minoristas, así como los empresarios que facilitan servicios de viaje vinculados, aunque declaren que actúan exclusivamente como prestadores de un servicio de viaje, como intermediarios o en cualquier otra calidad, o que los servicios que prestan no constituyen un viaje combinado o servicios de viaje vinculados".
} 
viaje que integran los servicios de viaje vinculados (salvo, claro está, en el caso de que el empresario facilitador sea, además, prestador de un servicio de viaje, pues en este caso responderá de la no ejecución o ejecución defectuosa de este servicio).

La contratación de los servicios de viaje o del servicio de viaje adicional siempre se realizará con la ayuda (facilitación) del empresario, pero esa facilitación puede adquirir una naturaleza jurídica diversa. Así, en ciertos casos la relación jurídica que nace entre el empresario y el viajero será podrá calificarse de comisión mercantil ${ }^{45}$ [lo que puede ser frecuente cuando los servicios de viaje vinculados se contratan en un único punto de venta -art. 151.1.e) $1^{\mathrm{o}}$-], ya que el empresario facilitador celebrará los contratos de servicios de viaje con el prestador del servicio en nombre y por cuenta del viajero. En otras, sin embargo, la naturaleza de la actividad desarrollada por el empresario facilitador se asemejará a la mediación, ya que se limitará a poner en contacto a las dos partes, celebrándose el contrato del servicio de viaje directamente entre ellos [cuando los servicios de viaje se contratan a través de páginas webs enlazadas -art. 151.1.e) $2^{\mathrm{o}}$-].

Debe tenerse en cuenta que los contratos que componen los servicios de viaje vinculados tienen su propio régimen jurídico (transporte, hospedaje, etc.) y que, además, quedan sometidos a las normas generales en materia de contratación, cobrando aquí especial relevancia la aplicación del régimen de los contratos a distancia con consumidores contenido en el TRLGDCU (Libro II, Título III) y las normas sobre contratación electrónica de la $\operatorname{LSSICE}^{46}$. Nótese que el artículo 93 del TRLGDCU excluye del ámbito de aplicación del régimen de los contratos a distancia a los viajes combinados, pero no a los servicios de viaje vinculados. Ello tiene sentido debido a que la propia norma, al regular en el Libro IV los viajes combinados, contiene normas de protección de los consumidores. Esto no ocurre, sin embargo, con la regulación que el Libro IV ofrece de los servicios de viaje vinculados que, como veremos, limita la protección del consumidor a recibir información precontractual sobre el tipo de contrato que está celebrando y a protegerle frente a la insolvencia del empresario facilitador de los servicios de viaje vinculados. No obstante, debido a que la noción de viajero no coincide con la de consumidor, puede suceder que en ciertos casos el usuario de los servicios turísticos sea un viajero a efectos de aplicarle lo previsto en el Libro IV del TRLDGCU, pero no sea un consumidor, por lo que no se aplicarán las normas concretas de defensa de estos.

\subsection{Facilitación de la contratación por el empresario en la forma legalmente prevista: clases de servicios de viaje vinculados}

Una de las características esenciales de los servicios de viaje vinculados es que, aun tratándose de servicios de viaje contratados con cada prestador del servicio, la contratación se realiza

\footnotetext{
${ }^{45}$ BATUECAS CALETRIO (“La contratación de viajes vinculados”, op., cit., pp. 12-15) califica la relación de mandato.

${ }^{46}$ Vid. GONZÁLEZ CABRERA, I., “El contrato de viaje combinado...”, op. cit., p. 151.
} 
gracias a la labor de facilitación de un empresario, que es la que justifica que los diversos servicios de viaje queden vinculados ${ }^{47}$. Así, si es el empresario el que organiza (en sentido amplio) el viaje estamos ante viajes combinados; si es el viajero quien asume esta tarea, ante servicios de viaje sueltos; si el viajero organiza el viaje con la ayuda del empresario, entonces la situación será la de servicios de viaje vinculados.

La norma ha optado por fijar los casos en los que existe esa labor facilitadora, diferenciando dos supuestos distintos: contratación de los servicios de viaje en único punto de venta ${ }^{48}$ (que podrá ser un local físico o una página web) o contratación de los servicios en varias páginas webs enlazadas (distintos puntos de venta). Ambos tienen en común -y los diferencian de los viajes combinados- que existe una separación en el proceso de reserva de cada servicio de viaje, de forma que una reserva se completa íntegramente antes de seleccionar el siguiente servicio de viaje ${ }^{49}$.

En primer lugar, existirán servicios de viaje vinculados si el empresario facilita "con ocasión de una única visita o contacto con su punto de venta, la selección y el pago separado de cada servicio de viaje por parte de los viajeros" [art. 151.1.e) $1^{\circ}$ ]. La exigencia de que cada servicio de viaje sea seleccionado y pagado de forma separada permite afirmar que debe existir una clara separación entre los procesos de reserva ${ }^{50}$, de manera que uno se haya completado antes de seleccionar el siguiente servicio de viaje. No es necesario, sin embargo, que se haya realizado el pago del primer servicio de viaje, bastando el compromiso de pago que implica la confirmación de la reserva (por ejemplo, se reserva una habitación de hotel -que se abonará posteriormente- $\mathrm{y}$ tras la confirmación de la reserva se adquiere un billete de avión). Lo esencial es, por tanto, que se haya perfeccionado el contrato sobre el primer servicio de viaje antes de

\footnotetext{
${ }^{47}$ En este sentido resulta bastante clarificadora la definición que de minorista ofrecía la Propuesta de Directiva (art. $3^{\circ}$, letra $\mathrm{m}$ ): "operador distinto del organizador que a) vende u oferta viajes combinados o b) facilita la adquisición de servicios de viaje que forman parte de un servicio asistido de viaje ayudando a los viajeros a celebrar contratos separados para servicios de viaje con proveedores de servicios individuales" (el subrayado es nuestro).

${ }^{48}$ El artículo 151.1.m) TRLGDCU define el punto de venta como "toda instalación de venta al por menor, tanto mueble como inmueble, o un sitio web de venta al por menor o un dispositivo similar de venta minorista en línea, incluso cuando estos dispositivos se presenten a los viajeros como un dispositivo único, incluido un servicio telefónico".

${ }^{49}$ Cfr. DEPARTMENT FOR BUSINESS, ENERGY \& INDUSTRIAL STRATEGY, The Package Travel and Linked Travel..., op.cit., p. 22. El precepto plantea numerosos problemas a la hora de su aplicación a los supuestos que se dan en la práctica. Prueba de ello lo constituyen las diversas preguntas realizadas en relación con los servicios de viaje vinculados en los diversos workshops celebrados por la Comisión Europea con los Estados miembros (como se ha indicado previamente, los documentos que recogen las cuestiones analizadas en los sucesivos workshops celebrados están disponibles en https://ec.europa.eu/newsroom/just/itemdetail.cfm?item_id=35324). De gran interés resulta en este punto el contenido del documento Industry Guidance EU Package Directive, de 18 de junio de 2018, elaborado por la European Technology and Travel Services Association (ETTSA), que se encuentra disponible en https://eutraveltech.eu/wpcontent/uploads/2019/11/ETTSA-publishes-Industry-Guidance-for-compliance-with-EU-Package-TravelDirective.pdf.

${ }^{50}$ Señala BERENGUER ALBALADEJO ("Luces y sombras de la nueva Directiva...”, op.cit., p. 41) que en este caso hay dos procesos de reserva distintos.
} 
que se inicie el proceso de contratación del segundo servicio de viaje ${ }^{51}$. Adicionalmente, la exigencia de que se realice una selección y pago separado de cada servicio de viaje permite diferenciar estos supuestos de los viajes combinados ex art. 151.1.b) $2^{\circ}$ i) TRLGDCU, que califica como viaje combinado las combinaciones de viajes en los que los servicios de viaje son contratados en único punto de venta, pero son seleccionados antes de que el viajero acepte pagar.

El precepto exige, además, que la contratación de los diferentes servicios se realice en el mismo momento, esto es, con ocasión de una única visita o contacto con el punto de venta; de lo contrario, se estarían contratando servicios de viaje sueltos ${ }^{52}$. Pueden surgir problemas en torno a lo que se considera una única visita o contacto con el punto de venta (piénsese en los casos en los que se producen problemas de conexión a Internet o en el propio funcionamiento de la web, o en el supuesto de que se acuda a última hora de la tarde a la agencia de viajes y se posponga la contratación del segundo servicio de viajes para el día siguiente). Se ha señalado, en este sentido, que debe haber una clara interrupción para que pueda afirmarse que no existe una única visita o contacto ${ }^{53}$.

Cuando la contratación de los servicios de viaje se realiza en forma electrónica, se plantea el problema de determinar qué ocurre en los casos en los que en la web del empresario facilitador se inserta publicidad de otros prestadores de servicios o intermediarios. La intención del legislador es diferenciar la actividad publicitaria de la actividad de facilitación, excluyendo la primera del ámbito de aplicación de la norma ${ }^{54}$. La cuestión reside en que la línea que separa ambas actividades puede ser muy delgada $\mathrm{y}$, además, difícilmente reconocible por el consumidor. Podemos poner como ejemplo la práctica comercial de alquiler de espacios publicitarios. Y es que, en efecto, aun cuando de la lectura de las condiciones generales pueda inferirse cuáles son los servicios ofertados y cuáles los meramente publicitados por un empresario, la impresión que puede ofrecer la forma en que dichos servicios aparecen en la web (punto de venta) es que no hay diferencia entre unos y otros ${ }^{55}$.

\footnotetext{
${ }^{51}$ Vid. COMISIÓN EUROPEA, Transposition of Directive (EU) No 2015/2302 on Package Travel and Linked Travel Arrangements Workshop with Member States on 16 February 2017, p. 11.

${ }^{52}$ A través de la web de una OTA se adquiere un billete de avión y al día siguiente se reserva a través de la misma página una habitación de hotel en el lugar de destino. En este caso, se estarían contratando servicios de viaje sueltos. Si la contratación de los dos servicios de viaje se hubiera realizado en la misma visita a la web (el primer día), podrían haberse formado servicios de viaje vinculados. Si en la misma página web y en la misma visita se hubiera seleccionado el avión y el hotel antes de aceptar pagar, existiría un viaje combinado.

${ }^{53}$ Cfr. DEPARTMENT FOR BUSINESS, ENERGY \& INDUSTRIAL STRATEGY, The Package Travel and Linked Travel..., op. cit., p. 23.

${ }^{54}$ Vid. Considerando 12 de la Directiva 2015/2302.

${ }^{55}$ Apunta este problema PANIZA FULLANA, A., Viajes combinados y servicios de viaje vinculados..., op. cit., p. 109.
} 
No es necesario, sin embargo -tal y como se deduce de la definición de "punto de venta" que ofrece la norma- que los servicios de viaje se contraten electrónicamente; se incluyen, por tanto, los casos en los que la contratación de los distintos servicios de viaje se realiza de manera presencial en una agencia de viajes. Por lo demás, el empresario facilitador podrá ser tanto una agencia de viajes o central de reservas como un prestador de servicios de viaje (por ejemplo, una aerolínea) que permita contratar en su web otros servicios de viaje adicionales a los que él mismo presta.

En segundo lugar, la combinación de servicios de viaje da lugar a la formación de servicios de viaje vinculados si el empresario facilita "de manera específica, la contratación de al menos un servicio de viaje adicional con otro empresario, siempre que tenga lugar a más tardar veinticuatro horas después de la confirmación de la reserva del primer servicio de viaje" [art. 151.1.e) $2^{\circ}$ ]. Aun cuando la norma no excluye su aplicación a los casos de contratación presencial $^{56}$, parece que está considerando los supuestos en los que la contratación de los distintos servicios de viaje se realiza a través de páginas webs enlazadas (así parece confirmarlo el contenido de los formularios D y E del Anexo III que se han incorporado al TRLGDCU) ${ }^{57}$. Sería el caso de un viajero que contrata un vuelo en la página web de una aerolínea y desde la página de confirmación del vuelo recibe una invitación para reservar un hotel a través de un enlace. Si el viajero reserva el hotel dentro de las veinticuatro horas desde la confirmación de la primera reserva, los servicios de viaje vinculados se habrán formado. Ahora bien, nada impide que en un futuro (o actualmente) existan otras formas de contratación que puedan encajar en el supuesto descrito.

Al igual que ocurre con el supuesto examinado anteriormente (servicios de viaje que se contratan en un único punto de venta), también aquí existen similitudes con uno de los casos en los que el legislador entiende que la combinación debe calificarse de viaje combinado. Nos referimos al supuesto contemplado en el artículo 151.1.b) $2^{\circ} . \mathrm{v}$ ) TRLGDCU: los servicios de viaje "son contratados con distintos empresarios a través de procesos de reserva en línea conectados en los que el nombre del viajero, sus datos de pago y su dirección de correo electrónico son transmitidos por el empresario con el que se celebra el primer contrato a otro $\mathrm{u}$ otros empresarios con quienes se celebra otro contrato, a más tardar veinticuatro horas después de la confirmación de la reserva del primer servicio de viaje". En ambos casos se trata de reservas en línea efectuadas en diferentes webs (click trough bookings ${ }^{58}$. Debe entenderse que

\footnotetext{
${ }^{56}$ La Propuesta de Directiva, por el contrario, limitaba esta segunda modalidad de servicios de viaje vinculados a los casos en los que la contratación de los servicios de viaje se realizaba en línea [vid., al respecto, art. $3^{\circ} 5 . b$ ) de la Propuesta de Directiva y COMISIÓN EUROPEA, Transposition of Directive (EU) No 2015/2302 on package travel and linked travel arrangements Workshop with Member States on 25 February 2015, p. 8].

${ }^{57}$ El Anexo III recoge los formularios con la información normalizada que el empresario que facilita servicios de viaje vinculados debe proporcionar a los viajeros (sobre el contenido de los formularios y su función vid. infra el apartado 3. Deberes y obligaciones del empresario facilitador).

${ }^{58}$ Ambos supuestos (viajes combinados y servicios de viaje vinculados contratados en línea a través de distintas páginas webs) constituyen el objeto del Informe de la Comisión al Parlamento Europeo y al Consejo sobre las
} 
para que la combinación pueda calificarse de viaje combinado y no de servicios de viaje vinculados deberán trasmitirse todos los datos señalados. Bastaría, por tanto, con que no se transmitieran los datos de pago del viajero para que la relación no pudiera calificarse de viaje combinado. Esta afirmación puede cobrar relevancia en la medida en que no es frecuente que los empresarios se transmitan los datos de pago de los viajeros. Precisamente por ello, y al objeto de que puedan ser calificados como viajes combinados, se ha abogado por la eliminación del requisito de la transmisión de los datos de pago del viajero para que la relación jurídica pueda calificarse como viaje combinado ${ }^{59}$.

La exigencia de que el segundo contrato "tenga lugar" a más tardar veinticuatro horas después de la confirmación de la primera reserva constituye una manifestación de una de las características de los servicios de viaje vinculados apuntadas anteriormente: la contratación de los diferentes servicios de viaje debe realizarse en el mismo momento. Ahora bien, para el caso de que la contratación se realice mediante páginas webs enlazadas, el legislador ha optado por flexibilizar este requisito, permitiendo que transcurra un lapso de tiempo entre la celebración de ambos contratos ${ }^{60}$. El plazo de veinticuatro horas empieza a contar desde que el viajero recibe la confirmación de la reserva del primer servicio de viaje ${ }^{61}$. En cuanto a qué debe entenderse por "siempre que tenga lugar" (el segundo contrato), debe entenderse que la reserva del segundo servicio de viaje debe realizarse antes de que hayan transcurrido veinticuatro horas desde la recepción de la confirmación de la reserva del primer servicio de viaje ${ }^{62}$.

disposiciones de la Directiva (UE) 2015/2302 del Parlamento Europeo y del Consejo, de 25 de noviembre de 2015, relativa a los viajes combinados y a los servicios de viaje vinculados que se aplican a reservas en línea efectuadas en diferentes puntos de venta [COM (2019) 270 final, Bruselas, 21.6. 2019, disponible en https://eurlex.europa.eu/legal-content/ES/TXT/PDF/? uri=CELEX:52019DC0270\&from=ES]. Como complemento de este Informe se publicó el documento Commission Staff Working document accompanying the document Report from de Commission to the European Parlament and the Council on the provisions of Directive (UE) 2015/2302 of the European Parliament and of the Council of 25 november 2015 on package travel and linked travel arrangements applying to online bookings made at different point of sale [SWD (2019) 270 final, Brussels, 21.6.2019], que ofrece información adicional a la contenida en el Informe. El documento se encuentra disponible en https://eurlex.europa.eu/legal-content/MT/TXT/?uri=CELEX:52019SC0270.

${ }^{59}$ Vid. Commission Staff Working document accompanying the document Report..., op. cit., p. 5.

${ }^{60}$ En la Propuesta de Directiva la contratación del segundo servicio de viaje tenía que hacerse en el momento en que se confirmara la reserva del primer servicio [art. $\left.3^{\circ} 5 . b\right)$ ].

${ }^{61} \mathrm{Si}$ bien el texto del artículo no especifica que el plazo comienza desde la recepción de la confirmación de la reserva, sí que lo indica el formulario D del Anexo III ("antes de veinticuatro horas desde la recepción de la confirmación de la reserva"). No encontramos, sin embargo, esta referencia en el formulario E, aunque sí aparece en la versión en inglés de la Directiva 2015/2302. La confirmación de la reserva cumpliría las funciones del acuse de recibo exigido por el artículo 28 LSSICE, como confirmación de la aceptación por parte del prestador del servicio de viaje.

${ }^{62}$ En este sentido, el Informe de la Comisión al Parlamento Europeo y al Consejo sobre las disposiciones de la Directiva (UE) 2015/2302 (op. cit., p. 3) indica que tanto en los casos de viajes combinados a los que se accede con un click como en los de servicios de viaje vinculados a los que se accede de la misma forma, "el viajero debe reservar el segundo servicio de viaje en un plazo de veinticuatro horas desde la reserva del primer servicio de viaje". 
El requisito temporal se convierte en esencial y determinante de la existencia o no de servicios de viaje vinculados ${ }^{63}$. Asume la norma, de esta manera, uno de los caracteres que la práctica y la doctrina han venido atribuyendo a los paquetes dinámicos: la exigencia de que los distintos servicios turísticos se contraten en un mismo momento. Ahondando en la cuestión, surge el interrogante de por qué esa exigencia. A nuestro modo de ver, la razón de esa simultaneidad (o cuasi simultaneidad) estriba en que de algún modo hay que delimitar en qué supuestos existen servicios de viaje vinculados y en cuáles solo se produce la adquisición de servicios de viaje sueltos. El requisito de que los distintos servicios de viaje se adquieran para "el mismo viaje o vacación" no es suficiente, por tanto, para que se produzca la vinculación ${ }^{64}$. Ahora bien, esto puede originar que un empresario "evite" la aplicación del régimen de los servicios de viaje vinculados retrasando la facilitación del segundo servicio de viaje (el empresario con el que se celebra un contrato sobre un servicio de viaje no envía el enlace en el correo en que se confirma la reserva, sino posteriormente y, más concretamente, trascurridas veinticuatro horas desde que se celebró el primer contrato).

Por otro lado, la inclusión de la expresión "de manera específica" pretende dejar fuera del ámbito de aplicación de la norma supuestos en los que el empresario facilita el enlace a otra $\mathrm{u}$ otras páginas webs pero con una función informativa o publicitaria ${ }^{65}$. En estos casos, el empresario no actúa como intermediario en la contratación de otros servicios de viaje, sino como prestador de servicios de la sociedad de la información ${ }^{66}$ quedando, por tanto, sometido a las disposiciones de la LSSICE. Así, aun cuando no es necesario para que existan servicios de viaje vinculados que el empresario facilitador transmita ciertos datos del viajero al segundo empresario $^{67}$, la transmisión de datos como el destino o las fechas del viaje pueden ser determinantes para entender que estamos ante servicios de viaje vinculados y no ante un reenvío a otras webs con fines meramente informativos o publicitarios ${ }^{68}$. La finalidad perseguida por el

\footnotetext{
${ }^{63}$ Sobre la relevancia del elemento temporal en la calificación jurídica de la relación que se establece vid. PANIZA FULLANA, A., Viajes combinados y servicios de viaje vinculados..., op. cit., pp. 18-19.

${ }^{64}$ En este sentido, el Considerando 12 de la Directiva señala que "los servicios de viaje vinculados deben distinguirse de los servicios de viaje que los viajeros reservan de manera autónoma, a menudo en diferentes momentos, aunque se destinen a un mismo viaje o vacación.
}

65 Vid. Considerando 12 de la Directiva; DEPARTMENT FOR BUSINESS, ENERGY \& INDUSTRIAL STRATEGY, The Package Travel and Linked Travel..., op. cit., p. 24. Aunque en relación con los viajes combinados vid. GONZÁLEZ CABRERA, I., "El contrato de viaje combinado..., op. cit., p. 128.

${ }^{66} \mathrm{Vid}$. Anexo 2 (Información específica para hoteles) y 5 (Información específica para otros productos o servicios ofrecidos por terceros) de los Términos y Condiciones de Edreams (vid. https://www.edreams.es/condicionesgenerales-de-venta/, consultada el 24 de marzo de 2021). No obstante, ha de tenerse en cuenta que para la calificación del servicio que se oferta (viaje combinado, servicios de viaje vinculados o servicios de viaje sueltos) no se tendrá en cuenta la declaración que en relación a la naturaleza del servicio realice el empresario, sino que deberá atenderse a la realidad y, por tanto, a su encaje en los supuestos regulados en el TRLGDCU (vid., al respecto, art. 151.3 TRLGDCU).

${ }^{67}$ Vid. COMISIÓN EUROPEA, Workshop with Member States on 25 October 2016, op. cit., p. 17.

${ }^{68}$ Vid. DEPARTMENT FOR BUSINESS, ENERGY \& INDUSTRIAL STRATEGY, The Package Travel and Linked Travel..., op. cit., p. 32. Este podría ser el sentido de la disposición añadida en la norma de derecho alemán (651w, Absatz 1, 2. Unterabsatz, BGB), que dispone que no se cumple este requisito (que la contratación del 
precepto es que la contratación del segundo servicio de viaje no sea producto de una publicidad o información general que proporcione un empresario, sino de una promoción especifica de servicios de viaje relacionados con el que el viajero acaba de contratar. Cobraría así sentido que se exija que se contrate un servicio de viaje adicional, término que no puede interpretarse simplemente en que se destine al mismo viaje o vacación -pues ello ya se exige antes- sino que se añade a o adiciona a la reserva del primer servicio de viaje ${ }^{69}$. En cualquier caso, se trata de un requisito que, por su indeterminación, plantea en la práctica problemas a la hora de dilucidar qué tipo de actividades de un empresario son a priori susceptibles de ser encuadradas en el supuesto contemplado por la norma -esto es, si debe entenderse que facilitan la contratación de un servicio de viaje adicional ${ }^{70}$.

Al igual que ocurre con los servicios de viaje vinculados que se forman tras su contratación en un único punto de venta, en el supuesto que estamos analizando tanto el empresario facilitador como el segundo empresario (es decir, aquél con el que el viajero contrata el servicio de viaje adicional) podrán ser agencias de viaje, centrales de reservas o prestadores de servicios de viaje. No exige la norma que entre el empresario facilitador y el empresario con el que el viajero contrata el servicio de viaje adicional exista una relación comercial remunerada, pero lo cierto es que normalmente la habrá ${ }^{71}$.

Por último, y a fin de que el empresario facilitador tenga conocimiento de que el segundo contrato se ha celebrado y de que, en consecuencia, los servicios de viaje vinculados se han formado, se impone al empresario con el que se contrata el segundo servicio de viaje el deber de informar al empresario facilitador de la celebración de este segundo contrato ${ }^{72}$. No se establecen, sin embargo, consecuencias para el incumplimiento de este deber por parte del segundo empresario que, por otro lado, puede ser frecuente en la práctica bien por desconocimiento, bien porque no disponga de los medios técnicos necesarios para identificar al empresario facilitador, bien porque ello supondría un incremento del precio que debe pagar

servicio de viaje adicional se facilite de manera específica) cuando el empresario facilitador únicamente pone en contacto al viajero con otro empresario.

${ }^{69}$ Vid. COMISIÓN EUROPEA, Workshop with Member States on 25 February 2015, op. cit., p. 8.

${ }^{70}$ En este sentido, existen dudas sobre si la facilitación "de manera específica" requiere o no una promoción activa del segundo contrato por parte del empresario facilitador y si la provisión de anuncios relevantes (generales) está cubierta por la Directiva (vid. Commission Staff Working document accompanying the document Report..., op. cit., p. 7).

${ }^{71}$ Vid. Considerando 13 de la Directiva 2015/2302, que señala además que el cálculo de la remuneración puede basarse en el número de clicks o en el volumen de ventas. Llama en este punto la atención el hecho de que para los paquetes dinámicos sí se ha venido señalando como una de sus características que ha de mediar una relación comercial entre ambos empresarios.

${ }^{72}$ Vid. art. 168.3 TRLGDCU. No es necesario que el viajero haya dado su consentimiento para dicha transmisión de datos, ya que en estos casos el tratamiento de los datos es necesario para el cumplimiento de una obligación legal [vid. art. $6^{\circ}$.c) del Reglamento 2016/679, de Protección de Datos y art. $8^{\circ}$ Ley Orgánica 3/2018, de 5 de diciembre, de Protección de Datos Personales y garantías de los derechos digitales]. 
al empresario que le facilita el link ${ }^{73}$. No es este, sin embargo, el único problema que plantea el deber de información del segundo empresario respecto al empresario facilitador, tal y como está configurado en la norma. Y ello porque no se exige que el empresario facilitador, una vez que el segundo empresario le ha informado de la celebración del contrato de viaje adicional, confirme al viajero que se han formado los servicios de viaje vinculados. Esto puede plantear problemas al viajero a la hora de intentar hacer efectiva la garantía por la insolvencia del empresario facilitador, en la medida en que no dispone de un documento en el que se indique expresamente que, efectivamente, los servicios de viaje por él contratados forman parte de unos servicios de viaje vinculados ${ }^{74}$. Aun cuando el viajero podría servirse de confirmaciones de correos electrónicos, capturas de pantalla, etc., entendemos que la norma debería haber impuesto de forma expresa al empresario facilitador el deber de informar al viajero de la formación de los servicios vinculados y facilitar al viajero un certificado que acredite el derecho a reclamar la garantía, y ello para las dos modalidades que contempla el artículo 151.1.e) del TRLGCU ${ }^{75}$.

Como se ha indicado previamente, en las dos modalidades de servicios de viaje vinculados que prevé el TRLGDC, el empresario facilitador podrá ser tanto un empresario que realice actividades de intermediación (agencia de viajes, central de reservas) ${ }^{76}$ como un prestador de servicios de viaje. Cuando el empresario facilitador no es un prestador de servicios actúa como intermediario en la contratación de los servicios de viaje que forman los servicios de viaje vinculados. Cuando sí lo es, a su condición de prestador de servicios del primer servicio de viaje añade la prestación de un servicio adicional: la de intermediación en la contratación del segundo (o sucesivos) servicios de viaje. La cuestión radica entonces en determinar la naturaleza de esta labor de intermediación. Dada las diferentes formas en que se puede realizar la contratación del segundo o sucesivos servicios de viaje quizás no pueda hablarse de una única naturaleza jurídica. Así, cuando la contratación se lleva a cabo mediante páginas webs

\footnotetext{
${ }^{73}$ Vid. Commission Staff Working document accompanying the document Report..., op. cit., p. 7.

${ }^{74}$ La cuestión apuntada en el texto se abordó en uno de los workshops celebrados por la Comisión Europea (vid. COMISIÓN EUROPEA, Workshop with Member States on 16 February 2017, op . cit., pp. 7-8), en el que se puso de manifiesto la preocupación porque los empresarios pusieran obstáculos cuando los viajeros quisieran hacer efectiva la garantía. No parece que el deber del empresario facilitador de confirmar al viajero la formación de los servicios de viaje vinculados pueda fundamentarse en el artículo 28 LSSICE, que hace referencia al acuse de recibo de la recepción de la aceptación.

75 La obligación de emitir un certificado sí se contempla para los viajes combinados [el artículo 155.2.c) TRLGDCU, siguiendo lo indicado en el Considerando 39 de la Directiva 2015/2302, establece que “(L)os Estados miembros deben poder exigir que los organizadores faciliten a los viajeros un certificado que acredite el derecho a reclamar directamente al que sea garante en caso de insolvencia"]. No obstante, ciertas normas autonómicas han extendido la obligación de emitir el certificado a los servicios de viaje vinculados (vid., por ejemplo, art. 13.3 Decreto 51/1998, de 24 de febrero, del Gobierno de Aragón, por el que se aprueba el Reglamento de las Agencias de Viaje).

${ }^{76}$ Así, por ejemplo, los Términos y Condiciones de la central de reservas esky.es contemplan de forma expresa la posibilidad de contratar servicios de viaje vinculados (vid. https://www.esky.es/terminos-y-condiciones, consultada el 19 de marzo de 2021).
} 
enlazadas (segundo supuesto), la relación jurídica podría calificarse de contrato de mediación. Cuando se facilita la contratación en la misma página web, podría tratarse bien de un contrato de comisión bien de una mediación dependiendo de cómo se haya celebrado el contrato.

\section{DEBERES Y OBLIGACIONES DEL EMPRESARIO FACILITADOR}

Con la finalidad de aumentar el nivel de protección de los viajeros, el TRLGDCU impone a los empresarios que facilitan servicios de viaje vinculados el deber de informar a aquéllos sobre la naturaleza de la relación jurídica que se va a establecer y la obligación de constituir una garantía frente a su insolvencia.

\subsection{Deber de información precontractual}

El artículo 168 TRLGDCU dispone que el empresario facilitador, antes de que el viajero quede obligado por cualquier contrato que dé lugar a servicios de vinculados o por cualquier oferta correspondiente, indicará de forma clara, comprensible y destacada que la relación jurídica que va a establecer no es un viaje combinado (y que, por tanto, el viajero no gozará de los derechos que la ley reconoce en estos casos); que cada prestador de servicios es el único responsable de la correcta ejecución de su prestación ${ }^{77}$; y que el viajero gozará de la protección frente a la insolvencia del empresario que facilita los servicios de viaje vinculados ${ }^{78}$. La imposición al empresario del deber de informar acerca de la naturaleza de la relación jurídica que se va a establecer supone el reconocimiento por parte del legislador de la dificultad que existe en la

\footnotetext{
${ }^{77}$ Esta es una de las principales diferencias entre los viajes combinados y los servicios de viaje vinculados: la ausencia de responsabilidad del empresario facilitador por los incumplimientos de los prestadores de los servicios de viaje que integran la combinación. El viajero, por tanto, ante posibles incumplimientos contractuales, deberá dirigirse contra el prestador del servicio de viaje, determinándose la responsabilidad de éste de conformidad con el régimen jurídico que resulte de aplicación a dicho servicio de viaje [vid. MARCO ARCALÁ, L.A., "La regulación de los servicios de viaje vinculados. La prescripción de las reclamaciones y el régimen sancionador", en El nuevo régimen de los viajes combinados y servicios de viaje vinculados en el Derecho español, Valencia, Tirant lo Blanch, 2020 (edición digital), p. 296].

${ }^{78}$ Deber de información que, tal y como señala el precepto, se impone también a los empresarios no establecidos en un Estado miembro pero que por cualquier medio ofrezcan servicios de viaje vinculados en España (sobre esta cuestión vid., más ampliamente, MARCO ARCALÁ, L.A., "La regulación de los servicios de viaje vinculados...", op. cit., pp. 287-288). Destaca este mismo autor (op. cit., p. 299), que el viajero debe ser informado de las diferencias entre los viajes combinados y los servicios de viaje vinculados, para que "sepa en todo momento lo que contrata y en qué condiciones y con qué requisitos en cada caso". Como es posible que los servicios de viaje vinculados no se formen debido no ya a que no se cumpla el requisito temporal, sino a que la combinación únicamente incluye un servicio de viaje principal y los servicios de viaje secundarios no cumplen lo establecido en el artículo 151.1.e) TRLGDCU, párrafo segundo, se ha sugerido que podría incluirse en los formularios del Anexo III una indicación de que la protección frente a la insolvencia solo existirá en los casos en que los servicios de viajes secundarios representen una proporción igual o superior al veinticinco por ciento del valor de la combinación, o no se anuncien o no constituyen por alguna otra razón un requisito esencial del viaje o vacación [vid. COMISIÓN EUROPEA, Transposition of Directive (EU) No 2015/2302 on Package Travel and Linked Travel Arrangements Workshop with Member States on 18 May 2017, p. 5].
} 
práctica de diferenciar un viaje combinado, tras la ampliación del concepto realizada por la Directiva, de los servicios de viaje vinculados ${ }^{79}$.

La información señalada debe "proporcionarse al viajero" mediante unos formularios normalizados que se recogen en el Anexo III del TRLGDCU (art. 168.2 TRLGDCU) ${ }^{80}$ antes de que el viajero quede obligado por cualquier contrato que dé lugar a servicios de viaje vinculados o por cualquier oferta correspondiente (art. 168.1 TRLGDCU) ${ }^{81}$. Los términos utilizados por el artículo 168.2 (y que hemos entrecomillado) permiten afirmar que la información debe facilitarse al viajero en relación con el proceso de contratación que ha iniciado. No bastaría con que los formularios estuvieran disponibles en el sitio web del empresario que facilita los servicios de viaje, ya que el artículo 168.2 no establece un deber de información general sobre la oferta de servicios de viaje vinculados, sino un deber de información sobre un concreto contrato -el segundo- que, de celebrarse, dará lugar a servicios de viaje vinculados, pero no a un viaje combinado. Si la contratación es presencial, el empresario facilitador deberá entregar en mano el formulario que proceda y si es en forma electrónica deberá aparecer de forma destacada (la información misma o el enlace que permite al acceso al formulario).

La duda que suscita la redacción del 168.1 es si la información debe proporcionarse antes de la celebración del primer contrato de servicio de viaje, o después de celebrado el primer contrato de viaje y antes de que se celebre el segundo. El tenor literal del texto parece avalar la segunda interpretación, ya que técnicamente el contrato que "da lugar" a los servicios de viaje vinculados es el segundo y no el primero. Además, dado que la finalidad esencial del deber de información legalmente establecido es la de advertir al viajero que el producto turístico que va

79 Vid. PANIZA FULLANZA, A., Viajes combinados y servicios de viaje vinculados..., op. cit., p. 113; GONZÁLEZ CABRERA, I., "El contrato de viaje combinado...”, op. cit., p. 152.

\footnotetext{
${ }^{80}$ Art. 168. 2 TRLGDCU: “(A) fin de cumplir con lo dispuesto en el presente apartado, el empresario que facilite unos servicios de viaje vinculados proporcionará al viajero dicha información mediante el formulario normalizado correspondiente que figura en el anexo III. Cuando el carácter especial de los servicios de viaje vinculados no esté contemplado por ninguno de los formularios que figuran en dicho anexo proporcionará la información contenida en el mismo". El último inciso está pensado para los supuestos en que los servicios de viaje vinculados ofrecidos no se ajustan a ninguna de las formas descritas en los formularios del Anexo III, facultando al empresario facilitador para modificar alguno de ellos al objeto de que ofrezca una información clara y adecuada. El Anexo III contiene cinco formularios distintos. Los formularios A (el empresario facilita servicios de viaje vinculados en línea y es un transportista que vende un billete de ida y vuelta), B (el empresario facilita servicios de viaje vinculados en línea pero no es un transportista que vende un billete de ida y vuelta) y C (el empresario que facilita los servicios de viaje vinculados no es un transportista que vende un billete de ida y vuelta y los contratos se celebran presencialmente) se refieren a la información normalizada de los servicios de viaje vinculados contemplados en el artículo 151.1.e) $1^{\circ}$ TRLGDCU; y los formularios D (el empresario facilita servicios de viaje vinculados en línea y es un transportista que vende un billete de ida y vuelta) y E (el empresario facilita servicios de viaje vinculados en línea pero no es un transportista que vende un billete de ida y vuelta) a la relativa a los supuestos contemplados en el artículo 151.1.e) $2^{\circ}$ TRLGDCU.
}

${ }^{81}$ Señala BERENGUER ALBALADEJO (“Luces y sombras de la nueva Directiva...”, op. cit., p. 44) que el precepto no hace referencia al medio o forma en que se ha de proporcionar la información, indicando que bastaría con añadir que debe hacerse "en soporte duradero". 
a adquirir no es un viaje combinado, aquélla se alcanza situando el deber de información en un momento anterior a la formación de los servicios de viaje vinculados. Esta interpretación resulta avalada por el contenido de los formularios E y D del Anexo III [para los supuestos del art. 151.1.e) $2^{\circ}$ ], del que se desprende que el empresario facilitador proporcionará al viajero la información del artículo 168 cuando confirme la reserva del primer servicio de viaje y le facilite el enlace del segundo empresario ${ }^{82}$ (es decir, una vez celebrado el primer contrato y antes de que perfeccione el segundo).

A este deber de información con respecto al proceso de contratación iniciado se uniría el deber del empresario facilitador, en tanto que oferente de servicios de viaje vinculados, de poner a disposición de los potenciales viajeros información sobre el producto ofrecido antes de que se celebre el contrato sobre el primer servicio de viaje. Y ello con base en los artículos 18 y 60 TRLGDCU (cuando el viajero es un consumidor y con independencia de la forma en que se realice la contratación), 97 TRLGDCU (si el viajero es consumidor y el contrato se celebra a distancia -lo que incluye la contratación electrónica y telefónica-) y 27 LSSICE (para todo tipo de viajero, siempre que la contratación sea en forma electrónica). Por las peculiaridades propias de los servicios de viaje vinculados, la información (que bastará con que esté disponible en la página web del empresario) habrá de indicar de forma clara y comprensible que el viajero podrá vincular diversos servicios de viaje y los requisitos necesarios para que esa vinculación se produzca (es decir, debe quedar claro que el empresario oferta servicios de viaje vinculados). Para ello, entendemos que debe hacerse referencia expresa (incluso mediante su transcripción literal), al contenido del artículo 151.1.e) del TRLGDCU y poner a disposición, también en este momento, los formularios del Anexo III.

Y es que, como señala el considerando 16 de la Directiva $2015 / 2302^{83}$, para que el viajero tenga una capacidad real de elección entre las diversas fórmulas o tipos de viaje, no solo es relevante que sea informado de que no está contratando un viaje combinado (art. 168.1) sino, además, de que puede, en lugar de adquirir servicios de viaje sueltos para un mismo viaje o vacación, vincular esos servicios de viaje. Quien tiene proyectado un viaje que requiera, por ejemplo, un transporte y un alojamiento, si no es informado de que puede vincular ambos servicios normalmente no lo sabrá, de forma tal que no quedará protegido frente a la insolvencia del empresario que, de facto, ofrece la posibilidad técnica de vincular esos servicios. Desde el mismo momento en que un empresario permite que en su página web se contraten varios servicios de viaje, o que colabora con otro empresario para que éste ofrezca al viajero servicios

\footnotetext{
82 Tanto el formulario D como el E comienzan señalando lo siguiente: "(S)i usted reserva unos servicios adicionales para su viaje o vacación mediante este(os) enlace(s)...”.

83 “(P)ara que las condiciones estén más claras para los viajeros y estos puedan elegir con conocimiento de causa entre los diferentes tipos de fórmulas de viaje ofertadas...”. En el mismo sentido, la Comunicación de la Comisión "Adaptar la normativa europea sobre viajes combinados a la era digital" (op. cit., p. 10), señala que "es fundamental que los consumidores comprendan plenamente qué se les ofrece y puedan elegir con confianza los servicios de viaje que mejor se adapten a sus necesidades específicas".
} 
de viaje adicionales, el primer empresario está ofertando servicios de viaje vinculados. Por tanto, la información sobre las condiciones que deben darse para producirse la vinculación (contratación en el mismo momento, o dentro de las veinticuatro horas) debe ponerse a disposición del viajero antes de que este celebre el primer contrato de servicio de viaje ya que de esta manera el viajero tendrá la posibilidad real de vincular los servicios.

Con respecto al deber de información sobre la existencia de una garantía frente a la insolvencia, el precepto debería añadir que dicha protección existirá únicamente si el viajero contrata el servicio de viaje adicional en los términos que recoge el artículo 151.1.e) TRLGDCU. Tal precisión sí se recoge en los formularios del Anexo III, pero en nuestra opinión debería haber ido en el texto del artículo.

El TRLGDCU no se pronuncia sobre a quién corresponde la carga de la prueba del cumplimiento de los deberes de información en relación con los servicios de viaje vinculados. Entendemos que debe recaer sobre el empresario que los facilita, por aplicación analógica de la solución prevista por el legislador en el artículo 156 TRLGCDU para los viajes combinados $^{84}$. Por último, aun cuando no menos importante, se prevén importantes consecuencias de carácter jurídico-privado para los casos en los que el empresario que facilita los servicios de viaje vinculados no ha cumplido con sus deberes de información, que consisten en que a los servicios de viaje vinculados se les aplicará parte del régimen jurídico de los viajes combinados (art. 168.2 TRLGCDU ${ }^{85}$ ). Así, se reconocen al viajero dos de los derechos que ostentan los viajeros en los viajes combinados: el derecho a ceder los contratos que formen parte de los servicios de viaje vinculados (art. 157) y el derecho de resolver los mismos (art. 160); y se prevé la aplicación a los servicios de viaje vinculados del régimen de ejecución del viaje combinado (arts. 161 a 163). Aunque la remisión al régimen de los viajes combinados puede no ser la forma más adecuada para establecer el régimen jurídico aplicable en los casos señalados ${ }^{86}$, las similitudes que presentan los servicios de viaje vinculados con los viajes combinados del artículo 151.1.b) $2^{\circ}$ i) -servicios de viaje contratados en un único punto de venta y seleccionados antes de que el viajero acepte pagar- y v) -contratados con distintos empresarios a través de procesos de reserva en línea conectados-, permiten afirmar que la forma

\footnotetext{
${ }^{84}$ Art. 156 TRLGDCU: "La carga de la prueba en relación con el cumplimiento de los requisitos de información establecidos en este capítulo recaerá en el empresario".

${ }^{85}$ Art. 168.2 TRLGDCU: "Si el empresario que facilite servicios de viaje vinculados no ha cumplido con los requisitos establecidos en el artículo 167 y en el apartado 1 de este artículo, se aplicarán los derechos y obligaciones establecidos en los artículos 157 y 160 y en el Capítulo IV del Título II de este libro en relación con los servicios de viaje que forman parte de los servicios de viaje vinculados". Como se desprende del precepto reproducido, se ha previsto idéntica sanción para los casos en los que el empresario facilitador no ha constituido la garantía frente a la insolvencia en los términos señalados en el artículo 167. Sobre las consecuencias del incumplimiento del deber de información vid., más ampliamente, MARCO ARCALÁ, L.A., "La regulación de los servicios de viaje vinculados...", op. cit., pp. 297-302.

${ }^{86}$ Vid. en este sentido, con relación a los derechos de cesión y resolución reconocidos por esta vía al viajero que contrata servicios de viaje vinculados, BATUECAS CALETRIO, A., "La contratación de viajes vinculados", op. cit., p. 12.
} 
en que los derechos de cesión del contrato y de resolución se articulan en los viajes combinados del artículo 151.1.b) $2^{\circ}$, apartados i) y v) puede servir de guía o modelo para los servicios de viaje vinculados, haciéndose extensible esta afirmación a lo relativo a la ejecución del contrato de viaje combinado.

\subsection{Obligación de constituir una garantía frente a su insolvencia}

Al objeto de aumentar la protección de los viajeros y promover una competencia leal, se impone al empresario que facilita los servicios de viaje vinculados la obligación de constituir una garantía que cubra el reembolso de todos los pagos que reciba de los viajeros para el caso de que alguno de los servicios de viaje que integran los servicios de viaje vinculados no se ejecute como consecuencia de su insolvencia (la del empresario facilitador). La garantía deberá cubrir también la repatriación de los viajeros si el empresario facilitador es el responsable del transporte (art. 167 TRLGDCU) ${ }^{87}$. No se exige, sin embargo, la constitución de la garantía por incumplimiento contractual, en la medida en que el empresario facilitador no responde de la ejecución de los distintos servicios de viaje incluidos en la combinación.

El obligado a prestar esta garantía es, por tanto, el empresario que facilita los servicios de viaje vinculados, ya se trate de una agencia de viajes o central de reservas o de un prestador de servicios de viajes (aerolínea, establecimiento hotelero) ${ }^{88}$. De esta manera se garantiza que los diversos tipos de empresarios que ofertan combinaciones de servicios de viaje lo hagan en las mismas condiciones competitivas. En efecto, al ser los servicios de viaje vinculados una alternativa a los viajes combinados -podría decirse que se trata de productos turísticos que compiten entre sí- los empresarios que los ofertan deben quedar sometidos a unas reglas comunes en materia de garantías frente a la insolvencia. Se evita, de esta manera, que determinados empresarios (los que facilitan servicios de viaje vinculados) se encuentren en mejor posición que los organizadores-minoristas en el contrato de viaje combinado.

La garantía cubre, como señala la norma, todos los pagos que el empresario facilitador reciba de los viajeros y se establece para los casos en los que alguno de los servicios de viaje incluidos en la combinación no se ejecute como consecuencia de la insolvencia ${ }^{89}$ del empresario que los

\footnotetext{
${ }^{87}$ El contenido de los formularios del Anexo III matiza lo afirmado en el artículo 167, ya que solo contempla que la garantía cubra la repatriación en los casos en los que el empresario facilitador sea un transportista que vende un billete de ida y vuelta (vid. formularios A y D).

${ }^{88} \mathrm{Se}$ ha denunciado que algunas aerolíneas están ofreciendo viajes combinados y servicios de viaje vinculados sin constituir estas garantías (vid. https://www.hosteltur.com/132339_acave-denuncia-a-varias-aerolineas-que-noofrecen-garantias-al-viajero.html, consultada el 24 de marzo de 2021).

${ }^{89}$ Según dispone el apartado 3 del artículo 167, la insolvencia se entiende producida "tan pronto como sea evidente que por la falta de liquidez de los empresarios los servicios de viaje dejen de ejecutarse, no vayan a ejecutarse o vayan a ejecutarse solo en parte, o cuando los prestadores de servicios requieran a los viajeros pagar por ellos". No parece, como se ha señalado por la doctrina, que se trate de la insolvencia prevista en la Ley concursal [sobre las relaciones entre la insolvencia en el régimen jurídico de los viajes combinados y los servicios de viaje vinculados y la insolvencia concursal vid. GONZÁLEZ CABRERA, I., "Medidas de protección del consumidor frente a la insolvencia de los operadores turísticos: seguros, fianzas y otras garantías", Revista de Derecho
} 
ha facilitado ${ }^{90}$. El precepto parte de la base de que el empresario facilitador ha recibido del viajero fondos que corresponden al pago de los distintos servicios de viaje que integran los servicios de viaje vinculados. Si el empresario facilitador deviene insolvente antes de haber remitido los fondos al prestador del servicio de viaje, éste se negará a prestar el servicio al viajero. No entraría, por tanto, en juego la garantía, en los casos en los que empresario facilitador no tiene los fondos, bien porque ya se los ha entregado al prestador del servicio de viaje, bien porque el viajero ha pagado directamente al prestador del servicio ${ }^{91}$.

Por tanto, es importante resaltar que la garantía no se constituye para proteger al viajero frente a la insolvencia de los prestadores de servicios de viaje, sino para protegerle frente a la insolvencia del empresario facilitador cuando dicha insolvencia hace que no puedan ejecutarse los servicios de viaje que integran los servicios de viaje vinculados. Tomemos como ejemplo el supuesto en el que el viajero reserva y paga de forma separada en la web de una agencia de viajes un billete de avión y una habitación de hotel. En el caso de que la agencia devenga insolvente antes de entregar los fondos al hotel, este denegará al viajero el alojamiento o le obligará a pagar por él. En este caso, un servicio de viaje deja de ejecutarse (el alojamiento) por la insolvencia del empresario facilitador (la agencia de viajes) $\mathrm{y}$, por tanto, los fondos entregados por el viajero en pago de la habitación están cubiertos por la garantía. No obstante,

Bancario y Bursátil, núm. 152, 2018 (edición digital), especialmente el apartado III.2; GONZÁLEZ CABRERA, I., "La escasa protección del turista en el ámbito de La Unión Europea: al hilo de la insolvencia de Thomas Cook", Diario La Ley, núm. 9502, 2019 (edición digital); BENAVIDES VELASCO, P., "La obligación de las agencias de viaje de prestar las garantías contempladas en la Directiva de viajes combinados", International Journal of Scientific Management and Tourism, 2018, pp. 102-104; MARCO ARCALÁ, L.A., "La nueva regulación de las garantías en los viajes combinados y en los servicios de viaje vinculados", en El nuevo régimen de los viajes combinados y servicios de viaje vinculados en el Derecho español, Valencia, Tirant lo Blanch, 2020 (edición digital), pp. 259-260]. En este sentido, la CNMC en su Informe sobre el Anteproyecto de Ley de transposición de la Directiva (vid. Informe de la CNMC sobre el Anteproyecto de Ley..., op. cit., p. 10), señalaba la conveniencia de que la norma de trasposición diferenciase esta insolvencia de la que contempla la Ley concursal, para evitar confusiones en cuanto al régimen aplicable.

${ }^{90}$ Aun cuando la cuestión había suscitado algunas dudas, se trata, en efecto, de la insolvencia del empresario facilitador y no de la insolvencia de los prestadores de servicios de viaje que integran la combinación. Sobre esta cuestión y su evolución en el proceso de elaboración de la Directiva vid. BATUECAS CALETRIO, A., "La contratación de viajes vinculados", op. cit., pp. 16-17; BERENGUER ALBALADEJO, C., "Luces y sombras de la nueva Directiva..., op. cit., p. 41, nota núm. 24; PANIZA FULLANA, A., Viajes combinados y servicios de viaje vinculados..., op. cit., pp. 111-112. Vid., además, el Informe de la Comisión al Parlamento Europeo y al Consejo sobre las disposiciones de la Directiva (UE) 2015/2302..., op . cit., p. 1; GONZÁLEZ CABRERA, I., "La escasa protección del turista ...", op. cit., apartado 2.B. Por otro lado, al tratarse de servicios de viaje que no puedan ejecutarse por la insolvencia del empresario facilitador, la garantía no cubriría los pagos que dicho empresario haya recibido, en su caso, por otros conceptos distintos a los servicios de viaje como, por ejemplo, visados o seguros de viaje (vid. COMISIÓN EUROPEA, Workshop with Member States on 13 June 2016, op. cit., p. 7).

${ }^{91}$ Vid. DEPARTMENT FOR BUSINESS, ENERGY \& INDUSTRIAL STRATEGY, The Package Travel and Linked Travel..., op. cit., p. 25; COMISIÓN EUROPEA, Workshop with Member States on 25 February 2015, op. cit., p.17; Workshop with Member States on 13 June 2016, op. cit., pp. 16-17; y Workshop with Member States on 16 February 2017, op. cit., p. 8. 
en este caso, al no ser la agencia de viajes responsable del transporte, la garantía no cubriría la repatriación.

Lo que no queda del todo claro es si la garantía cubre los casos en los que el empresario facilitador es prestador de un servicio de viaje y, como consecuencia de su insolvencia, no se ejecuta su propio servicio de viaje. Pensemos en una combinación de hotel más forfaits de esquí en la que el hotel es prestador del servicio de alojamiento y facilitador de los forfaits. Si el viajero ha pagado los forfaits al hotel y éste no ha remitido los fondos al empresario que alquila los forfaits antes de devenir insolvente, la garantía cubrirá el pago de los forfaits. La duda es si esta garantía cubre, además, la estancia en el hotel (es decir, si el viajero podrá reclamar con cargo a la garantía lo abonado en concepto de estancia si ésta no puede realizarse debido a la insolvencia del establecimiento hotelero).

La interpretación que se ha realizado es que la garantía cubre también los casos en los que el servicio de viaje que no se presta como consecuencia de la insolvencia del empresario facilitador es su propio servicio de viaje ${ }^{92}$-en el ejemplo apuntado, cubriría también la estancia en el hotel-. Así parece deducirse de la dicción literal del precepto, que establece que la garantía cubre todos los pagos que los empresarios facilitadores reciban de los viajeros en la medida en que "uno de los servicios de viaje que estén incluidos" no se ejecute como consecuencia de la insolvencia de aquéllos. Y no puede discutirse que el servicio de viaje del empresario facilitador forma parte de los servicios de viaje vinculados.

Esta interpretación nos lleva a afirmar que la justificación de la imposición al empresario facilitador de la obligación de constituir una garantía frente a su insolvencia no es la misma en todos los casos, pudiendo distinguirse hasta tres supuestos distintos: a) el empresario facilitador es un empresario que no presta servicios de viaje (por ejemplo, una agencia de viajes o una central de reservas) y como consecuencia de su insolvencia no se presta alguno de los servicios de viaje incluidos en la combinación; b) el empresario facilitador es un empresario que presta servicios de viaje (por ejemplo, una aerolínea) y a causa de su insolvencia no presta alguno de los servicios de viaje distinto del servicio que él mismo presta; c) el empresario facilitador es un empresario que presta servicios de viaje y a consecuencia de su insolvencia no puede prestar su propio servicio de viaje.

En los supuestos a) y b), como se indicó previamente, la finalidad de la garantía es proteger los fondos entregados por los viajeros hasta que llegan a su legítimo propietario, que es el prestador del servicio. En el caso contemplado en la letra c), la razón de la imposición de esta obligación al empresario facilitador no puede ser la misma que la apuntada anteriormente, ya que los fondos entregados por el viajero están en manos de quien debe estar, esto es, del prestador del servicio de viaje.

\footnotetext{
${ }^{92}$ Vid. COMISIÓN EUROPEA, Workshop with Member States on 16 February 2017, op., cit., pp. 9-10.
} 
A nuestro modo de ver, y tratándose de una cuestión relevante, el precepto cuando menos suscita ciertas dudas interpretativas. Cuando el empresario facilitador presta un servicio de viaje asume un doble papel: prestador de un servicio de viaje y facilitador de la contratación de un servicio de viaje adicional. La obligación de constituir la garantía deviene de su condición de "facilitador" y únicamente en la medida en que tenga fondos de otros prestadores de servicios. Por tanto, si se quiere que la garantía cubra, además, los casos en los que la insolvencia del empresario facilitador imposibilita la prestación de su propio servicio de viaje, la norma debería haberlo establecido con mayor claridad, más aún cuando, a diferencia de lo que establecía la Propuesta de Directiva, el texto finalmente aprobado no incluye los supuestos de insolvencia de los prestadores de servicios ${ }^{93}$. Seguramente se ha querido que sea así -es decir, que la garantía cubra también a los viajeros en caso de que el servicio de viaje del empresario facilitador no pueda ejecutarse por su insolvencia- para dar solución a los problemas planteados por transportistas (fundamentalmente aerolíneas) que tras ser insolventes dejaban de prestar el servicio de transporte.

Como la interpretación que se ha dado al precepto es que la garantía cubre los pagos recibidos por el empresario facilitador por la prestación de su propio servicio de viaje (por ejemplo, si se trata de un transporte, la garantía cubriría el importe del billete), la protección del viajero se incrementa notablemente en los servicios de viaje vinculados con respecto a los casos en los que adquiere varios servicios de viaje para el mismo viaje o vacación pero que, por no cumplirse los requisitos establecidos en el artículo 151.1.e) se califican como servicios de viaje sueltos. De ahí la importancia, puesta de manifiesto anteriormente, de que los viajeros sean informados de la posibilidad de contratar servicios de viaje vinculados antes de que se celebre el contrato sobre el primer servicio de viaje.

Por lo que respecta a la repatriación la garantía que la cubra solo debe constituirse en los casos en los que el empresario facilitador sea un transportista y únicamente para los casos en los que vende un billete de ida y vuelta. No tienen, por tanto, que constituirla, ni las agencias de viaje ni las centrales de reserva cuando actúan como facilitadoras de servicios de viaje vinculados, ni los prestadores de servicios de transporte para aquellos casos en los que venden únicamente un billete de ida o de vuelta. Puede concluirse, por tanto, que, con la nueva regulación, al viajero que necesariamente vaya a incluir en su viaje el transporte, le interesan dos cosas: de un lado, adquirir el billete directamente al proveedor del transporte (y que el billete sea de ida y vuelta) y contratar los servicios de viaje adicionales en la forma prevista en el artículo 151.1.e) TRLGDCU.

\footnotetext{
${ }^{93}$ La Propuesta de Directiva [art. 17.b) y Considerando 34] se pronunciaba en términos más amplios, al incluir también los supuestos de insolvencia de los prestadores de los servicios de viaje (vid. BERENGUER ALBALADEJO, C., "Luces y sombras de la nueva Directiva...", op. cit., p. 41, nota núm. 24; BATUECAS CALETRIO, A., "La contratación de viajes vinculados", op. cit., p. 16). Los formularios del Anexo III contienen una referencia expresa a la exclusión de la insolvencia de los prestadores de servicios de viaje ("Tenga en cuenta que no se procederá al reembolso en caso de insolvencia del prestador de servicios correspondiente").
} 
La garantía podrá constituirse mediante la creación de un fondo de garantía, la contratación de un seguro, un aval u otra garantía financiera ${ }^{94}$, en los términos que determine la Administración competente, que serán las Comunidades Autónomas. Para dar cumplimiento a lo establecido en el artículo 167 TRLGDCU, las distintas leyes autonómicas habrán de modificar sus respectivas normas de turismo, a fin de incluir la obligación de los empresarios que faciliten servicios de viaje vinculados de constituir esta garantía. Así lo han hecho ya, entre otras, las Comunidades Autónomas de las Islas Baleares ${ }^{95}$, Cataluña ${ }^{96}$ y Aragón ${ }^{97}$.

Señalar, por último, que el incumplimiento de la obligación de constituir la garantía frente a la insolvencia lleva aparejada, según dispone el artículo 168.2 TRLGDCU, la misma consecuencia que se deriva del incumplimiento del deber de información establecido en el artículo 168.1, esto es, la aplicación de parte del régimen jurídico de los viajes combinados ${ }^{98}$.

\section{CONCLUSIONES}

Podemos, finalmente, y tras el análisis realizado, preguntarnos por el verdadero alcance de la nueva regulación de los servicios de viaje vinculados.

\footnotetext{
${ }^{94}$ Sobre las distintas formas que puede revestir la garantía vid. MARCO ARCALÁ, L.A., "La nueva regulación de las garantías...", op. cit., pp. 248-249.

95 Art. 59 bis Ley 8/2012, de Turismo de las Illes Balears: "Garantía de los viajes vinculados. Los empresarios domiciliados en las Illes Balears o que abran establecimiento en estas, que comercialicen estos tipos de servicios, definidos por la Directiva UE 2015/2302, del Parlamento Europeo y del Consejo, relativa a los viajes combinados y a los servicios vinculados, están obligados a mantener una garantía para cubrir su responsabilidad en casos de insolvencia, de conformidad con la Directiva mencionada y la normativa de transposición estatal, así como en los términos que se desarrollen reglamentariamente".
}

${ }^{96}$ Art. 252.11 y 12 Ley 22/2010, de 20 de julio, del Código de consumo de Cataluña:

“Artículo 252-11. Garantía de los servicios de viaje vinculados.

1. Se entiende por servicios de viaje vinculados los definidos por el artículo 3, apartado quinto, de la Directiva UE 2015/2302, del Parlamento Europeo y del Consejo, relativa a los viajes combinados y a los servicios de viaje vinculados.

2. Los empresarios que comercializan este tipo de servicios están obligados a mantener una garantía en los términos establecidos por el artículo 252-10, en caso de insolvencia, si el incumplimiento se deriva de su responsabilidad.

3. Esta garantía debe responder también por el retorno al origen y el alojamiento previo, en los casos en que la persona que ha comercializado el servicio es responsable del transporte".

“Artículo 252-12. Acreditación de disponibilidad de garantía suficiente.

Las personas, físicas o jurídicas, establecidas en Cataluña que comercializan u organizan viajes combinados o facilitan servicios de viaje vinculados deben presentar ante la ventanilla única empresarial una declaración responsable en la que manifiesten que disponen de la garantía que establecen los artículos anteriores".

97 Art. 13 Decreto 51/1998, de 24 de febrero, del Gobierno de Aragón, por el que se aprueba el Reglamento de Aragón de Agencias de Viajes.

${ }^{98}$ Vid. supra el epígrafe 3.1. Deber de información precontractual. 
En primer lugar, el legislador, al regular esta figura, establece las líneas que delimitan el viaje combinado. Al viaje combinado "ampliado" de la Directiva 2015/2302 había que ponerle ciertos límites pues, de lo contrario, la mayor parte de los contratos que tienen por objeto servicios de viaje y que se contratan en forma electrónica serían viajes combinados. Y estos límites se imponen estableciendo que determinadas combinaciones de servicios de viaje (los servicios de viaje vinculados) en apariencia iguales a ciertas combinaciones de servicios de viaje ahora calificadas como viajes combinados, no serán viajes combinados. Por tanto, la característica esencial de los servicios de viaje vinculados reside en que, a pesar de su apariencia, no son viajes combinados. Por este motivo, la obligación fundamental del empresario facilitador es la de informar al viajero de que no está contratando un viaje combinado (y que, por tanto, cada prestador de servicios será el único responsable del cumplimiento de su correspondiente prestación) y la rigurosa consecuencia que lleva aparejada el incumplimiento de esta obligación. Puede decirse que con la creación y regulación de los servicios de viaje vinculados el legislador quiere proteger al viajero potencial adquirente de una combinación de servicios de viaje que en apariencia podrían ser viajes combinados pero que realmente no lo son.

En segundo lugar, todo empresario que técnicamente permita vincular determinados servicios de viaje en la forma establecida en el artículo 151.1.e) TRLGDCU, se convierte de hecho en oferente de servicios de viaje vinculados. De ahí que, como señalábamos anteriormente, deba ponerse a disposición del viajero información sobre la oferta de servicios de viaje vinculados antes de que se celebre el contrato del primer servicio de viaje, ya que de esta forma podrá vincular los diversos servicios de viaje que pretende contratar. De esta manera se lograría no solo que el viajero estuviera advertido de que no va a contratar un viaje combinado sino, además, de que puede recurrir a una de las modalidades de contratación, los servicios de viaje vinculados, que le ofrecen una mayor protección que la adquisición de servicios de viaje sueltos.

En tercer lugar, la norma equipara en cierta medida a los prestadores de servicios de viaje con las agencias de viaje y con las centrales de reserva, en la medida en que desarrollen labores de intermediación en la contratación de servicios de viaje, obligando a los primeros a constituir una garantía para los casos en que devengan insolventes y como consecuencia de ello no puedan ejecutarse los servicios de viaje incluidos en la combinación. Se atiende así a las peticiones reiteradas de las agencias de viajes, que reclamaban un tratamiento equitativo, y se fomenta que todos los operadores que ofrezcan las mismas combinaciones estén sometidos a las mismas reglas.

\section{BIBLIOGRAFÍA}

APARICIO VAQUERO, J.P. - BATUECAS CALETRIO, A., "Régimen de responsabilidad en la prestación de servicios turísticos contratados como paquetes dinámicos", en Paquetes dinámicos: problemas y soluciones jurídicas desde una perspectiva 
internacional (dir. Paniza Fullana, A.), Madrid, Dykinson, 2014 (edición digital), pp. $55-90$.

BATUECAS CALETRIO, A., "La contratación de viajes vinculados", Revista Doctrinal Aranzadi Civil-Mercantil, núm. 6, 2016 (edición digital).

BATUECAS CALETRIO, A. - APARICIO VAQUERO, J.P., "La contratación on line de servicios turísticos", en Nuevas fórmulas de contratación on line de servicios turísticos: subsunción en los tipos legales y distribución de responsabilidad (coord. Paniza Fullana, A.), Granada, Comares, 2013, pp. 49-78.

BENAVIDES VELASCO, P., "La obligación de las agencias de viaje de prestar las garantías contempladas en la Directiva de viajes combinados", International Journal of Scientific Management and Tourism, 2018, pp. 93-114. Disponible en http://www.ijosmt.com/index.php/ijosmt/article/view/351.

BERENGUER ALBALADEJO, C., "Luces y sombras de la nueva Directiva (UE) 2015/2302 del Parlamento Europeo y del Consejo de 25 de noviembre de 2015, relativa a los viajes combinados y a los servicios de viaje vinculados", Internacional Journal of Scientific Managment Tourism, vol. 2, núm. 2, 2016, pp. 33-49. Disponible en http://www.ijosmt.com/index.php/ijosmt/article/view/93.

CAMACHO PEREIRA, CONSUELO: "La información precontractual en el ámbito de los viajes combinados tras la Directiva (UE) 2015/2302 del Parlamento Europeo y del Consejo, de 25 de noviembre de 2015, relativa a los viajes combinados y a los servicios de viaje vinculados", Revista de Derecho UNED, núm. 19, 2016. Disponible en http://revistas.uned.es/index.php/RDUNED/article/view/18464/15503.

CAMARGO GÓMEZ, J.D., "Contratación electrónica de paquetes dinámicos de turismo en el ordenamiento jurídico español”, Ars Iuris Salmanticensis, vol. 2, 2014, pp. 95-125. Disponible en https://revistas.usal.es/index.php/ais/issue/view/776.

COMISIÓN EUROPEA, Comunicación de la Comisión al Parlamento Europeo, al Consejo, al Comité Económico y Social Europeo y al Comité de las Regiones "Adaptar la normativa europea sobre viajes combinados a la era digital", COM (2013) 513 final, Bruselas, 9 de julio de 2013. Disponible en https://eur-lex.europa.eu/legalcontent/ES/TXT/PDF/? uri=CELEX:52013DC0513\&from $=E S$.

- Transposition of Directive (EU) No 2015/2302 on package travel and linked travel arrangements Workshop with Member States on 25 February 2015; Transposition of Directive (EU) No 2015/2302 on Package Travel and Linked Travel Arrangements Workshop with Member States on 13 June 2016; Transposition of Directive (EU) No 2015/2302 on Package Travel and Linked Travel Arrangements Workshop with 
Member States on 25 October 2016; Transposition of Directive (EU) No 2015/2302 on Package Travel and Linked Travel Arrangements Workshop with Member States on 16 February 2017; Transposition of Directive (EU) No 2015/2302 on Package Travel and Linked Travel Arrangements Workshop with Member States on 18 May 2017. Documentos disponibles en https://ec.europa.eu/newsroom/just/itemdetail.cfm?item_id=35324.

- Informe de la Comisión al Parlamento Europeo y al Consejo sobre las disposiciones de la Directiva (UE) 2015/2302 del Parlamento Europeo y del Consejo, de 25 de noviembre de 2015, relativa a los viajes combinados y a los servicios de viaje vinculados que se aplican a reservas en línea efectuadas en diferentes puntos de venta [COM (2019) 270 final, Bruselas, 21.6. 2019]. Disponible en https:/leur-lex.europa.eu/legalcontent/ES/TXT/PDF/? uri=CELEX:52019DC0270\&from $=$ ES.

- Commission Staff Working document accompanying the document Report from de Commission to the European Parlament and the Council on the provisions of Directive (UE) 2015/2302 of the European Parliament and of the Council of 25 november 2015 on package travel and linked travel arrangements applying to online bookings made at different point of sale [SWD (2019) 270 final, Brussels, 21.6.2019]. Disponible en https://eur-lex.europa.eu/legal-content/MT/TXT/?uri=CELEX:52019SC0270.

COMISIÓN NACIONAL DE LOS MERCADOS Y LA COMPETENCIA (CNMC), Informe sobre el Anteproyecto de Ley por la que se modifica el Texto Refundido de la Ley General para la Defensa de los Consumidores y Usuarios y otras Leyes complementarias, de 21 de diciembre de 2017 (IPN/CNMC/042/17). Disponible en https://www.cnmc.es/sites/default/files/1887234_5.pdf.

DEPARTMENT FOR BUSINESS, ENERGY \& INDUSTRIAL STRATEGY, The Package Travel and Linked Travel Arrangements Regulations 2018. Guide for businesses, United Kingdom, March, 2021. Disponible en https://assets.publishing.service.gov.uk/government/uploads/system/uploads/attachme nt_datalfile/967428/package-travel-and-linked-travel-arrangements-regulations2018.pdf.

\section{EUROPEAN TECHNOLOGY AND TRAVEL SERVICES ASSOCIATION (ETTSA),} Industry Guidance EU Package Directive, de 18 de junio de 2018. Disponible en https://eutraveltech.eu/wp-content/uploads/2019/11/ETTSA-publishes-Industry-

Guidance-for-compliance-with-EU-Package-Travel-Directive .pdf.

FELIÚ ÁLVAREZ DE SOTOMAYOR, S., Viajes combinados y servicios de viaje vinculados [Directiva (UE) 2015/2301] Cuestiones de ley aplicable, Madrid, Reus, 2018. 
FELIÚ REY, M.I., "La información y publicidad en la Directiva 2015/2302 de viajes combinados y servicios de viaje vinculados: del folleto informativo al hipervínculo", en Turismo y daños (coord. Mezzasoma, L. - Reyes López, M.J.), Pamplona, Aranzadi, 2019, pp. 45-72.

FERRER TAPIA, B., “Aspectos subjetivos de los paquetes dinámicos. La situación del consumidor", en Paquetes dinámicos: problemas y soluciones jurídicas desde una perspectiva internacional (dir. Paniza Fullana, A.), Madrid, Dykinson, 2014 (edición digital), pp. 31-54.

GONZÁLEZ CABRERA, I., “¿Es necesaria una regulación única y autónoma de las centrales de reserva para una mejor protección del consumidor o configurarlas como agencias de viajes?", Revista de Derecho Civil, vol. II, núm. 1, 2015, pp. 207-210;

- “ ¿Estamos ante el mismo producto si se adquiere en línea un viaje combinado o distintos servicios de viaje vinculados?”, Revista de Derecho Civil, vol. III, núm. 3, 2016, pp. 139-144;

- $\quad$ "Medidas de protección del consumidor frente a la insolvencia de los operadores turísticos: seguros, fianzas y otras garantías", Revista de Derecho Bancario y Bursátil, núm. 152, 2018 (edición digital);

- "El contrato de viaje combinado y los paquetes dinámicos (servicios de viaje vinculados)", en Manual de contratación turística (dir. Franch Fluxá, J.), Barcelona, Atelier, 2019, pp. 125-155; "La escasa protección del turista en el ámbito de La Unión Europea: al hilo de la insolvencia de Thomas Cook", Diario La Ley, núm. 9502, 2019 (edición digital).

GONZÁLEZ FERNÁNDEZ, M.B., "Redefiniciones y armonización en materia de viajes combinados”, Revista de Derecho Mercantil, núm. 297, 2019 (edición digital).

LONDON ECONOMICS, Study on Consumer Detriment in the area of Dinamic Packages. Final report to the European Commission - Health and Consumers DG, November 2009. Disponible en https://le-europe.eu/publication/study-on-consumer-detriment-inthe-area-of-dynamic-packages/.

MARCO ARCALÁ, L.A., "La nueva regulación de las garantías en los viajes combinados y en los servicios de viaje vinculados", en El nuevo régimen de los viajes combinados y servicios de viaje vinculados en el Derecho español, Valencia, Tirant lo Blanch, 2020 (edición digital), pp. 217-275;

"La regulación de los servicios de viaje vinculados. La prescripción de las reclamaciones y el régimen sancionador", en El nuevo régimen de los viajes combinados 
y servicios de viaje vinculados en el Derecho español, Valencia, Tirant lo Blanch, 2020 (edición digital), pp. 277-318.

MÁRQUEZ LOBILLO, P., "El consumidor en la contratación electrónica de servicios turísticos”, Revista de Derecho Mercantil, núm. 282, 2011, pp. 187-208.

MARTÍNEZ ESPÍN, P., "Impacto sobre la protección del consumidor de la Propuesta de Directiva del Parlamento Europeo y del Consejo relativa a los viajes combinados y los servicios asistidos de viaje, por la que se modifican el reglamento (CE) n 2006/2004 y la Directiva 2011/83/UE y por la que se deroga la directiva 90/314/CEE", Revista Doctrinal Aranzadi Civil-Mercantil, núm. 9, 2014 (edición digital);

- "La reforma del régimen de los viajes combinados y servicios de viaje vinculados", $L A$ LEY mercantil, núm. 55, 2019 (edición digital);

- $\quad$ "El nuevo régimen de los viajes combinados y servicios de viaje vinculados: una de cal y otra de arena", Centro de Estudios de Consumo, enero 2019, pp. 1-60. Disponible en http://centrodeestudiosdeconsumo.com.

MARTÍNEZ NADAL, A., "Las centrales electrónicas de reservas turísticas: breves consideraciones acerca de su naturaleza y régimen jurídico", en Estudios de Derecho mercantil. Libro homenaje al Prof. Dr. H.c. José Antonio Gómez Segade (coord. Tobío Rivas, A.M.), Madrid, Marcial Pons, 2013, pp. 967-984.

PANIZA FULLANA, A., "Nuevas tecnologías aplicadas al turismo y sus consecuencias jurídicas: los paquetes dinámicos”, en Paquetes dinámicos: problemas y soluciones jurídicas desde una perspectiva internacional (dir. Paniza Fullana, A.), Madrid, Dykinson, 2014 (edición digital), pp. 13-29; Viajes combinados y servicios de viaje vinculados: replanteamiento de conceptos y sus consecuencias sobre la responsabilidad, Madrid, Dykinson, 2017.

PEINADO GRACIA, J.I., "La protección del pasajero en el contrato de viaje combinado y en la prestación de servicios asistidos de viaje: la responsabilidad del transportista aéreo y de los operadores turísticos", en La responsabilidad del transportista aéreo y la protección de los pasajeros (dir. Guerrero Lebrón, M.J.), Madrid, Marcial Pons, 2015, pp. 513-560.

RAMÓN FERNÁNDEZ, F., "La transparencia e información en los contratos turísticos: viajes combinados y servicios de viaje vinculados”, en Turismo y daños (coord. Mezzasoma, L. - Reyes López, M.J.), Pamplona, Aranzadi, 2019, pp. 245-256.

ZUBIRI DE SALINAS, M., "Conceptos clave y responsabilidad en la nueva regulación de los viajes combinados y los servicios de viaje vinculados”, Revista europea de derecho de 
la navegación marítima y aeronáutica, núm. 34, 2017 (disponible en https://dialnet.unirioja.es/servlet/articulo?codigo=6450006);

"La reforma de la LGDCU para adaptar el Derecho español a la Directiva (UE) 2015/2302 del Parlamento Europeo y del Consejo, de 25 de noviembre de 2015, relativa a los viajes combinados y a los servicios de viaje vinculados", en El nuevo régimen de los viajes combinados y servicios de viaje vinculados en el Derecho español, Valencia, Tirant lo Blanch, 2020 (edición digital), pp. 25-54;

- "Los nuevos conceptos en materia de viajes combinados y servicios de viaje vinculados", en El nuevo régimen de los viajes combinados y servicios de viaje vinculados en el Derecho español, Valencia, Tirant lo Blanch, 2020 (edición digital), pp. 55-95. 